\title{
EFFECT OF INTERFACE PROPERTIES ON THE NONLINEAR BEHAVIOUR OF LONG-FIBRE-REINFORCED UNIDIRECTIONAL CERAMIC-MATRIX MINI-COMPOSITES SUBJECTED TO TENSILE AND FATIGUE LOADING
}

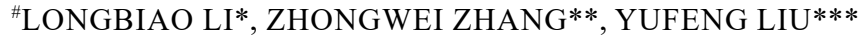 \\ *College of Civil Aviation, Nanjing University of Aeronautics and Astronautics \\ No.29 Yudao St., Nanjing 210016, PR China \\ **Institute of Advanced Structure Technology, Beijing Institute of Technology, Beijing 100081, PR China \\ ***Science and Technology of Advanced Functional Composite Materials Laboratory, \\ Aerospace Research Institute of Materials \& Processing Technology, Beijing 100076, PR China \\ \#E-mail: 1lb451@nuaa.edu.cn
}

Submitted January 15, 2020; accepted March 10, 2020

\begin{abstract}
Keywords: Ceramic-matrix composites (CMCs), Mini, Matrix cracking, Interface debonding, Fibre failure, Hysteresis loops
In this paper, the effect of the interface properties between the fibre and the matrix on the nonlinear behaviour of long-fibrereinforced unidirectional ceramic-matrix mini-composites (mini-CMCs) is investigated. The tensile nonlinear constitutive relationship and fatigue loading/unloading constitutive relationship are developed considering the different damage mechanisms of cracking in the matrix, debonding in the interface, and gradually the broken fibres. The relationships of the interface properties between the fibre and the matrix, the nonlinear tensile strain, and the fatigue loading/unloading hysteresis loops are established. The effects of the interface properties between the fibre and the matrix on the nonlinear tensile and fatigue loading/unloading damage evolution are analysed. The nonlinear tensile strain at the damage stage and the fracture strain of mini-CMCs decrease with the strong interface properties; and the fatigue loading/unloading hysteresis loops area and strain decrease, and the hysteresis modulus increases with the strong interface properties. The experimental tensile stressstrain curves and fatigue loading/unloading hysteresis loops of the Hi-Nicalon ${ }^{T M}$ and Tyranno ${ }^{T M} \mathrm{SiC} / \mathrm{SiC}$ mini-composites are predicted corresponding to the different interface properties.
\end{abstract}

\section{INTRODUCTION}

Ceramic-matrix composites (CMCs) are new types of thermal-structural-functional integrated materials with the advantages of metal materials, ceramic materials and carbon materials [1]. They have the characteristics of material-structural integration. Through the optimisation design of each structural unit, synergistic effects can be produced, and the high performance and reasonable matching of each performance can be achieved. Therefore, CMCs have high temperature resistance, corrosion resistance, wear resistance, a low density, a high specific strength and modulus, a low thermal expansion coefficient, insensitivity to cracks, no catastrophic damage and other advantages [2]. Since the 1990s, applications of CMCs have already been carried out in Europe and the United States on a demonstration and verification platform with thrust-to-weight ratios of 8-10 aeroengines (i.e., F119, EJ200, F414, M88-III, TRENT 800, etc.). The results show that fibre-reinforced CMCs can reduce the weight of stationary parts under moderate load by more than $50 \%$, and significantly improve their fatigue life. Generally speaking, intermediate-temperature and medium-load stationary parts such as a nozzle regulator/ seal have already completed a life-cycle verification and entered the stage of practical application and batch production; high-temperature and medium-load stationary parts, such as a combustion chamber flame tube and an inner and outer lining are undergoing a lifecycle verification and are expected to enter the practical application stage; while high-temperature and high-load rotating parts such as a turbine rotor and turbine blade are still in the exploratory research stage $[3,4]$.

The composite materials interface refers to the area with significant changes in chemical composition between the matrix and the reinforcing phase. The interface properties between the fibre and the matrix play an important role on the mechanical behaviour of fibrereinforced CMCs $[5,6]$. The interphase transfers the load between the fibre and the matrix after interface debonding, protects the fibre against an oxidative environment, and deflects the matrix cracking along the interface for the nonlinear behaviour of the CMCs $[7,8,9,10,11,12,13]$. When the fibre/matrix interface is strongly bonded, the fibre cannot play the role of load carrying, and the fibre-reinforced CMC fractures become brittle; and when the fibre/matrix interface is weakly bonded, the energy dissipation mechanisms 
of the interface debonding and fibre pullout are not obvious, which limits the nonlinear behaviour of the CMC. When the interface bonding between the fibre and the matrix is suitable, the reinforcing fibre can transfer the load and debonding at a high applied stress, which deflects the matrix cracking and increases the energy dissipation. The tensile and fatigue loading/unloading behaviour is affected by the interface properties (i.e., interface shear stress and interface debonding energy) between the fibre and the matrix $[14,15,16,17,18,19$, 20, 21]. Under tensile loading, the tensile stress-strain curves of fibre-reinforced CMCs can be divided into four different stages, i.e., (1) the linear-elastic stage, and the strain increases in direct proportion to the applied stress; (2) the damage stage with the matrix cracking and fibre debonding occurring at the interface, which makes the CMCs appear to have the characteristics of a pseudoplastic fracture and high toughness [22]; (3) the damage stage with the saturation of the matrix cracking and the complete fibre debonding at the interface [23, 24]; and (4) gradually, the fibre fracture stage $[25,26]$. The tensile properties including the elastic modulus, proportional limit stress, tensile strength, and fracture strain can be obtained through tensile tests, and used for the design of the CMC components [27]. Ahn et al. [28] investigated the interface deflection/penetration criterion at the fibre and the matrix interface using the energy release rate. Carrere et al. [29] investigated the matrix cracking deflection at the interphase of a mini-SiC/SiC composite with a Pyrocarbon (PyC) interphase. The deflection of the matrix cracking depends on the interface bond strength and interphase type. Sauder et al. [30] investigated the tensile and cyclic loading/unloading behaviour of a mini-SiC/SiC composite with a different interphase. The interphase thickness and the fibre surface roughness affect the tensile nonlinear and fracture strain of the mini-CMCs due to the different interface debonding conditions. Yu et al. [31] investigated the effect of the $\mathrm{SiC}$ coating thickness on the mechanical behaviour of a $\mathrm{SiC} / \mathrm{SiC}$ composite. The flexural strength of a $\mathrm{SiC} /$ $\mathrm{SiC}$ composite initially increased with the SiC coating thickness and reached a peak value, and then decreased rapidly, however, the bending modulus increased with the SiC coating thickness. Kabel et al. [32] investigated the relationship between the the $\mathrm{PyC}$ interphase properties and the debonding shear strength of a $\mathrm{SiC} / \mathrm{SiC}$ composite. Pryce and Smith [33] investigated the quasistatic tensile behaviour of a unidirectional and cross-ply $\mathrm{SiC} / \mathrm{CAS}$ composite at room temperature and monitored the evolution of the matrix cracking. Based on the shearlag model and experimental matrix cracking density, the tensile stress-strain curve of the unidirectional $\mathrm{SiC} / \mathrm{CAS}$ composite was predicted [34]. Chateau et al. [35] investigated the damage evolution of a unidirectional $\mathrm{SiC} / \mathrm{SiC}$ mini-composite using a $1 \mathrm{D}$ probabilistic model. The interfacial parameters are obtained by fitting the experimental characterisation. Morscher et al. [36] investigated the stress-dependent matrix cracking evolution of a $2 \mathrm{D}$ woven $\mathrm{SiC} / \mathrm{SiC}$ composite, and the relationship for the stress-dependent matrix cracking could be related to the stress in the load-bearing CVI SiC matrix. Li et al. [37] developed a micromechanical model to predict the tensile behaviour of a unidirectional $\mathrm{C} / \mathrm{SiC}$ composite, and established the relationship between the tensile curve and the internal damage mechanisms of the matrix cracking, interface debonding, and fibre failure. Li et al. [38] investigated the cyclic loading/unloading tensile behaviour of a unidirectional $\mathrm{C} / \mathrm{SiC}$ composite at room temperature. The effect of the fibre failure on mechanical hysteresis loops was considered. Li [39, 40] investigated the cyclic loading/unloading hysteresis loops of a cross-ply SiC/MAS composite under the outof-phase thermomechanical fatigue loading. The relationships between the phase angle, hysteresis loops, loading sequence, and environment temperature were established. The mini-composites (unidirectional composites containing a single bundle of fibres) were used to study the nonlinear behaviour of CMCs for different damage mechanisms $[41,42,43]$. The effect of the interface properties on the frictional heating [44, 45, 46], fatigue damage evolution $[47,48,49,50,51,52,53,54]$, and electrical resistance $[55,56]$ of unidirectional $\mathrm{SiC} / \mathrm{CAS}, 2 \mathrm{D} \mathrm{SiC} / \mathrm{SiC}$ composites were investigated. The interface properties affect the tensile and fatigue behaviour of the fibre-reinforced CMCs, especially the nonlinear tensile behaviour and the mechanical hysteresis loops. It is necessary to perform the investigations on the effect of the interface properties on the tensile and fatigue behaviour of the fibre-reinforced $\mathrm{CMCs}$, in order to establish the relationships between the interface properties and the mechanical behaviour of the CMCs.

In this paper, the nonlinear behaviour of mini-CMCs for different interface properties subjected to tensile and fatigue loading/unloading is investigated. The nonlinear constitutive models for the tensile and fatigue loading/ unloading hysteresis loops are developed considering the different damage mechanisms and interface properties. The effect of the interface properties on the nonlinear strain and fracture strain under tensile loading, fatigue loading/unloading hysteresis loops area, strain, and modulus is discussed. The experimental tensile strain and fatigue loading/unloading hysteresis loops of the $\mathrm{Hi}^{-N i c a l o n}{ }^{\mathrm{TM}}$ and Tyranno ${ }^{\mathrm{TM}} \mathrm{SiC} / \mathrm{SiC}$ mini-composites with different interphase properties are predicted.

\section{EXPERIMENTAL}

The Hi-Nicalon ${ }^{\mathrm{TM}} \mathrm{S}$ (Nippon Carbon Co. Ltd., Takauchi, Japan) and Tyranno SA3 (UBE Industries, Tokyo, Japan) tows reinforced $\mathrm{SiC}$ matrix ( $\mathrm{SiC} / \mathrm{SiC}$ ) mini-composites were fabricated using the chemical vapour infiltration (CVI) method. The $\mathrm{SiC}$ tows were coated with a single layer of pyrocarbon (PyC) with 
a thickness of 30 or $150 \mathrm{~nm}$, and a multilayer of $\mathrm{PyC}$ and $\mathrm{SiC}$ with a thickness of $150 \mathrm{~nm}$. The tensile and cyclic loading/unloading experimental results were performed and obtained per Sauder et al. [30]. The tensile and cyclic loading/unloading tests were performed at room temperature at a constant strain rate of $50 \mu \mathrm{m} \mathrm{min}{ }^{-1}$. The deformations of the mini-composite were measured using two-parallel linear-variable differential transformer extensometers.

\section{THEORETICAL}

In the present analysis, the constitutive models for the tensile and fatigue loading/unloading of the miniCMCs have been developed considering the multiple damage mechanisms and interface properties. The stochastic matrix cracking model, fracture mechanics approach, and Global Load Sharing (GLS) criterion are used to determine the space between the matrix cracking, fibre debonding length, fibre failure probability and intact fibre stress, respectively. Under fatigue loading/ unloading, the repeated sliding at the interface is taken into consideration for the mechanical hysteresis loops.

\section{Tensile constitutive model}

Under tensile loading, the nonlinear aspect of the CMCs is caused by the different damage mechanisms. In order to establish the nonlinear tensile constitutive model of the CMCs, the micro stress field of the fibre, matrix and the interface along the fibre direction for the multiple damage status should be analysed. When damage occurs, a unit cell is extracted from the mini-CMCs, as shown in Figure 1. The shear-lag model can be used to analyse the micro stress field of the damaged composite [57]. The fibre axial stress distribution can be determined using Equation 1 for the different damage regions [37].

$$
\sigma_{\mathrm{f}}(x)=\left\{\begin{array}{l}
\Phi-\frac{2 \tau_{\mathrm{i}}}{r_{\mathrm{f}}} x, x \in\left[0, l_{\mathrm{d}}\right] \\
\sigma_{\mathrm{fo}}+\left(\Phi-\sigma_{\mathrm{fo}}-2 \frac{l_{\mathrm{d}}}{r_{\mathrm{f}}} \tau_{\mathrm{i}}\right) \exp \left(-\rho \frac{x-l_{\mathrm{d}}}{r_{\mathrm{f}}}\right), \\
x \in\left[l_{\mathrm{d}}, l_{\mathrm{c}} / 2\right]
\end{array}\right.
$$

where $r_{f}$ denotes the fibre radius; $l_{\mathrm{d}}$ denotes the interface debonding length and can be determined using the fracture mechanics approach [37]; $l_{\mathrm{c}}$ denotes the matrix crack spacing and can be determined using the stochastic matrix cracking model [37]; $\sigma_{\text {fo }}$ denotes the fibre axial stress in the interface bonding region; $\rho$ denotes the shear-lag model parameter; $\tau_{\mathrm{i}}$ denotes the interface shear stress; and $\Phi$ denotes the intact fibre stress.

$$
l_{\mathrm{d}}=\frac{r_{\mathrm{f}}}{2}\left(\frac{V_{\mathrm{m}} E_{\mathrm{m}} \sigma}{V_{\mathrm{f}} E_{\mathrm{c}} \tau_{\mathrm{i}}}-\frac{1}{\rho}\right)-\sqrt{\left(\frac{r_{\mathrm{f}}}{2 \rho}\right)^{2}+\frac{r_{\mathrm{f}} V_{\mathrm{m}} E_{\mathrm{m}} E_{\mathrm{f}}}{E_{\mathrm{c}} \tau_{\mathrm{i}}^{2}} \zeta_{\mathrm{d}}}
$$

$$
l_{\mathrm{c}}=l_{\mathrm{sat}}\left\{1-\exp \left[-\left(\frac{\sigma_{\mathrm{m}}}{\sigma_{\mathrm{R}}}\right)^{m}\right]\right\}^{-1}
$$

where $V_{\mathrm{m}}$ denotes the matrix volume; $E_{\mathrm{m}}$ denotes the matrix elastic modulus; $E_{\mathrm{c}}$ denotes the composite elastic modulus; $\zeta_{\mathrm{d}}$ denotes the interface debonding energy; $l_{\text {sat }}$ denotes the saturation matrix crack spacing; $\sigma_{\mathrm{m}}$ denotes the matrix stress; $\sigma_{\mathrm{R}}$ denotes the matrix cracking characteristic stress; and $m$ denotes the matrix Weibull modulus.

Considering multiple damage mechanisms, the nonlinear constitutive relationship of the mini-CMCs can be determined using the following equation [37]:

$$
\begin{aligned}
\varepsilon_{\mathrm{c}}= & \frac{\Phi}{E_{\mathrm{f}}} \frac{2 l_{\mathrm{d}}}{l_{\mathrm{c}}}-\frac{\tau_{\mathrm{i}}}{E_{\mathrm{f}}} \frac{2 l_{\mathrm{d}}^{2}}{r_{\mathrm{f}} l_{\mathrm{c}}}+\frac{2 \sigma_{\mathrm{fo}}}{E_{\mathrm{f}} l_{\mathrm{c}}}\left(\frac{l_{\mathrm{c}}}{2}-l_{\mathrm{d}}\right)- \\
& -\frac{1}{\rho E_{\mathrm{f}}} \frac{2 r_{\mathrm{f}}}{l_{\mathrm{c}}}\left(\Phi-\sigma_{\mathrm{fo}}-2 \frac{l_{\mathrm{d}}}{r_{\mathrm{f}}} \tau_{\mathrm{i}}\right) \times \\
& \times\left[\exp \left(-\rho \frac{l_{\mathrm{c}} / 2-l_{\mathrm{d}}}{r_{\mathrm{f}}}\right)-1\right]-\left(\alpha_{\mathrm{c}}-\alpha_{\mathrm{f}}\right) \Delta \mathrm{T}
\end{aligned}
$$

where $\alpha_{f}$ and $\alpha_{c}$ denote the fibre and the composite thermal expansion coefficient, respectively; and $\Delta T$ denotes the temperature difference between the testing and fabricated temperature.

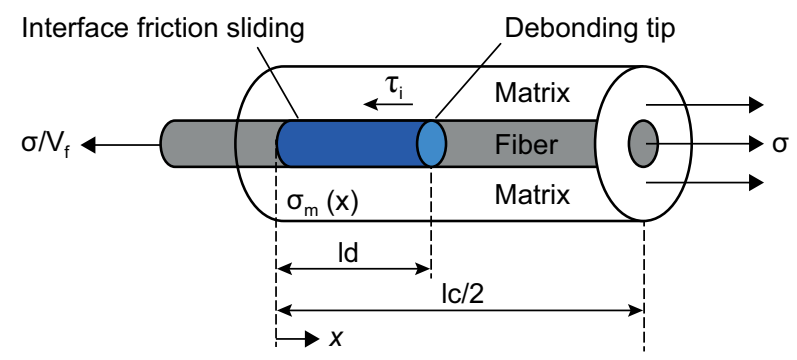

Figure 1. The unit cell of the shear-lag model.

\section{Fatigue loading/unloading constitutive model}

Under fatigue loading/unloading, the interface damage status affects the mechanical hysteresis loops. The fatigue loading/unloading constitutive model can be divided into two cases, i.e., (1) the partial debonding at the fibre interface; and, (2) the complete debonding at the fibre interface.

For the partial debonding at the fibre interface, the fatigue loading/unloading constitutive relationship can be determined using the following equations. [38]

$$
\begin{aligned}
\varepsilon_{\text {unloading }} & =\frac{\Phi_{U}}{E_{\mathrm{f}}}+4 \frac{\tau_{\mathrm{i}}}{E_{\mathrm{f}}} \frac{y^{2}}{r_{\mathrm{f}} l_{\mathrm{c}}}-\frac{\tau_{\mathrm{i}}}{E_{\mathrm{f}}} \frac{\left(2 y-l_{\mathrm{d}}\right)\left(2 y+l_{\mathrm{d}}-l_{\mathrm{c}}\right)}{r_{\mathrm{f}} l_{\mathrm{c}}}- \\
& -\left(\alpha_{\mathrm{c}}-\alpha_{\mathrm{f}}\right) \Delta \mathrm{T}
\end{aligned}
$$




$$
\begin{aligned}
\varepsilon_{\text {reloading }} & =\frac{\Phi_{R}}{E_{\mathrm{f}}}-4 \frac{\tau_{\mathrm{i}}}{E_{\mathrm{f}}} \frac{z^{2}}{r_{\mathrm{f}} l_{\mathrm{c}}}+4 \frac{\tau_{\mathrm{i}}}{E_{\mathrm{f}}} \frac{(y-2 z)^{2}}{r_{\mathrm{f}} l_{\mathrm{c}}}+ \\
& +2 \frac{\tau_{\mathrm{i}}}{E_{\mathrm{f}}} \frac{\left(l_{\mathrm{d}}-2 y+2 z\right)\left(l_{\mathrm{d}}+2 y-2 z-l_{\mathrm{c}}\right)}{r_{\mathrm{f}} l_{\mathrm{c}}}- \\
& -\left(\alpha_{\mathrm{c}}-\alpha_{\mathrm{f}}\right) \Delta \mathrm{T}
\end{aligned}
$$

where $\varepsilon_{\text {unloading }}$ denotes the unloading strain; and $\varepsilon_{\text {reloading }}$ denotes the reloading strain; $\Phi_{U}$ and $\Phi_{R}$ denote the intact fibres stress upon unloading and reloading, respectively; and $y$ and $z$ denote the interface counter-slip length and new-slip length, respectively.

For the complete debonding at the fibre interface, the fatigue loading/unloading constitutive relationship can be determined using the following equations [38]:

$$
\begin{aligned}
\varepsilon_{\text {unloading }} & =\frac{\Phi_{U}}{E_{\mathrm{f}}}+4 \frac{\tau_{\mathrm{i}}}{E_{\mathrm{f}}} \frac{y^{2}}{r_{\mathrm{f}} l_{\mathrm{c}}}-2 \frac{\tau_{\mathrm{i}}}{E_{\mathrm{f}}} \frac{\left(2 y-l_{\mathrm{c}} / 2\right)^{2}}{r_{\mathrm{f}} l_{\mathrm{c}}}- \\
& -\left(\alpha_{\mathrm{c}}-\alpha_{\mathrm{f}}\right) \Delta \mathrm{T} \\
\varepsilon_{\text {reloading }} & =\frac{\Phi_{R}}{E_{\mathrm{f}}}-4 \frac{\tau_{\mathrm{i}}}{E_{\mathrm{f}}} \frac{z^{2}}{r_{\mathrm{f}} l_{\mathrm{c}}}+4 \frac{\tau_{\mathrm{i}}}{E_{\mathrm{f}}} \frac{(y-2 z)^{2}}{r_{\mathrm{f}} l_{\mathrm{c}}}- \\
& -2 \frac{\tau_{\mathrm{i}}}{E_{\mathrm{f}}} \frac{\left(l_{\mathrm{c}} / 2-2 y+2 z\right)^{2}}{r_{\mathrm{f}} l_{\mathrm{c}}}-\left(\alpha_{\mathrm{c}}-\alpha_{\mathrm{f}}\right) \Delta \mathrm{T}
\end{aligned}
$$

\section{RESULTS AND DISCUSSION}

The interface properties affect the nonlinear mechanical behaviour of the CMCs, especially subjected to the tensile and fatigue loading/unloading conditions. For the $\mathrm{CMCs}$, the interface properties can be characterised using two parameters of the interface shear stress and the interface debonding energy. In this section, the effects of the interface properties on the nonlinear behaviour of the mini-CMCs subjected to the tensile and

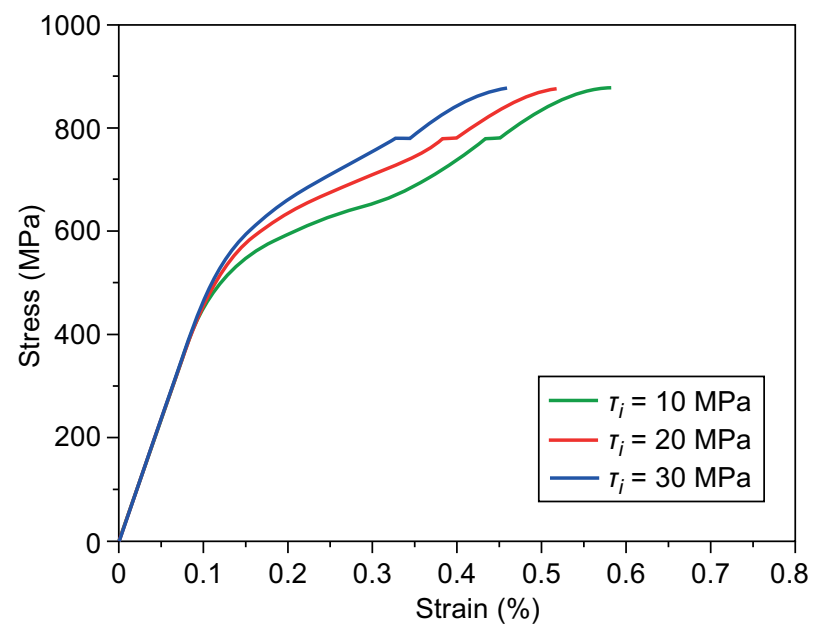

a) fatigue loading/unloading are analysed. The Hi-Nicalon ${ }^{\mathrm{TM}}$ Type S SiC/SiC mini-composite was used for the case analysis, and the material properties are given by [30]: $V_{f}=44 \%, E_{\mathrm{f}}=372 \mathrm{GPa}, E_{\mathrm{m}}=550 \mathrm{GPa}, r_{\mathrm{f}}=6.5 \mu \mathrm{m}$, $\alpha_{\mathrm{f}}=4.5 \times 10^{-6} /{ }^{\circ} \mathrm{C}, \alpha_{\mathrm{m}}=4.6 \times 10^{-6} /{ }^{\circ} \mathrm{C}, \Delta T=-1000{ }^{\circ} \mathrm{C}$, $\zeta_{d}=0.1 \mathrm{~J} \cdot \mathrm{m}^{-2}, \tau_{i}=20 \mathrm{MPa}$.

\section{Effect of the interface properties on tensile nonlinear strain}

Li and Song [59] developed an approach to estimate the interface shear stress of fibre-reinforced CMCs using hysteresis loops. The range of the interface shear stress of a unidirectional $\mathrm{SiC} / \mathrm{CAS}$ composite is between $\tau_{i}=10$ and $30 \mathrm{MPa}$. The effect of the interface shear stress (i.e., $\tau_{i}$ $=10,20$, and $30 \mathrm{MPa}$ ) on the tensile nonlinear strain and the interface debonding of the $\mathrm{SiC} / \mathrm{SiC}$ mini-composite is shown in Figure 2. When the interface shear stress increases from $\tau_{i}=10 \mathrm{MPa}$ to $\tau_{i}=30 \mathrm{MPa}$, the composite strain corresponding to the different damage stages of matrix cracking, interface debonding, and fibre failure decreases, and the composite failure strain decreases, due to the decrease in the interface debonding length. When the interface shear stress increases, the stress transfer between the fibre and the matrix increases, and the resistance to the interface debonding also increases, leading to a decrease in the interface debonding length and the nonlinear tensile strain [58]. The composite failure strain decreases from $\varepsilon_{f}=0.58 \%$ at $\tau_{i}=10 \mathrm{MPa}$ to $\varepsilon_{f}=0.47 \%$ at $\tau_{i}=30 \mathrm{MPa}$. The interface complete debonding stress increases with the interface shear stress. The interface complete stress increases from $\sigma=$ $660 \mathrm{MPa}$ at $\tau_{i}=10 \mathrm{MPa}$ to $\sigma=737 \mathrm{MPa}$ at $\tau_{i}=20 \mathrm{MPa}$.

Vagaggini et al. [60] investigated the constituent properties of fibre-reinforced CMCs using hysteresis loops. It was found that the value of the interface debonding energy is $\zeta_{d}=0 \sim 5 \mathrm{~J} \cdot \mathrm{m}^{-2}$. The effect of the interface debonding energy (i.e., $\zeta_{d}=1,2$, and $3 \mathrm{~J} \cdot \mathrm{m}^{-2}$ )

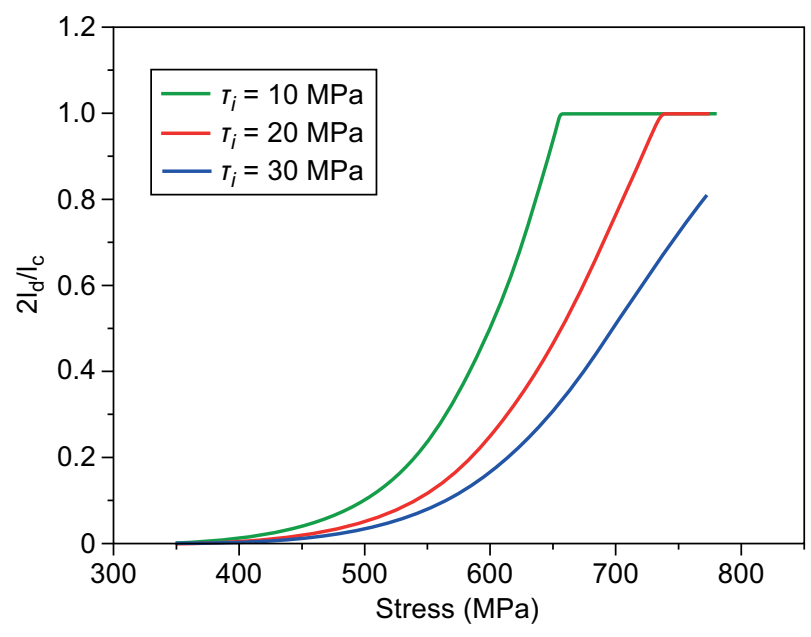

b)

Figure 2. The effect of the interface shear stress on: a) the tensile stress-strain curves; b) the interface debonding length versus the applied stress curves of the Hi-NicalonTM Type S SiC/SiC mini-composite. 
on the tensile nonlinear strain and the interface debonding of the $\mathrm{SiC} / \mathrm{SiC}$ mini-composite is shown in Figure 3. When the interface debonding energy increases from $\zeta_{d}=1 \mathrm{~J} \cdot \mathrm{m}^{-2}$ to $\zeta_{d}=3 \mathrm{~J} \cdot \mathrm{m}^{-2}$, the composite strain corresponding to the different damage stages decreases, and the composite failure strain decreases, due to the decrease in the interface debonding length. When the interface debonding energy increases, the energy needed for the interface debonding increases, leading to a decrease in the interface debonding length, and a decrease in the nonlinear strain. The composite failure strain decreases from $\varepsilon_{f}=0.53 \%$ at $\zeta_{d}=1 \mathrm{~J} \cdot \mathrm{m}^{-2}$ to $\varepsilon_{f}=0.4 \%$ at $\zeta_{\mathrm{d}}=$ $=3 \mathrm{~J} \cdot \mathrm{m}^{-2}$. At the same applied stress of $\sigma=780$, the interface debonding length decreases from $2 l_{\mathrm{d}} / l_{\mathrm{c}}=1.0$ at $\zeta_{\mathrm{d}}=1 \mathrm{~J} \cdot \mathrm{m}^{-2}$ to $2 l_{\mathrm{d}} / l_{\mathrm{c}}=0.38$ at $\zeta_{\mathrm{d}}=3 \mathrm{~J} \cdot \mathrm{m}^{-2}$.

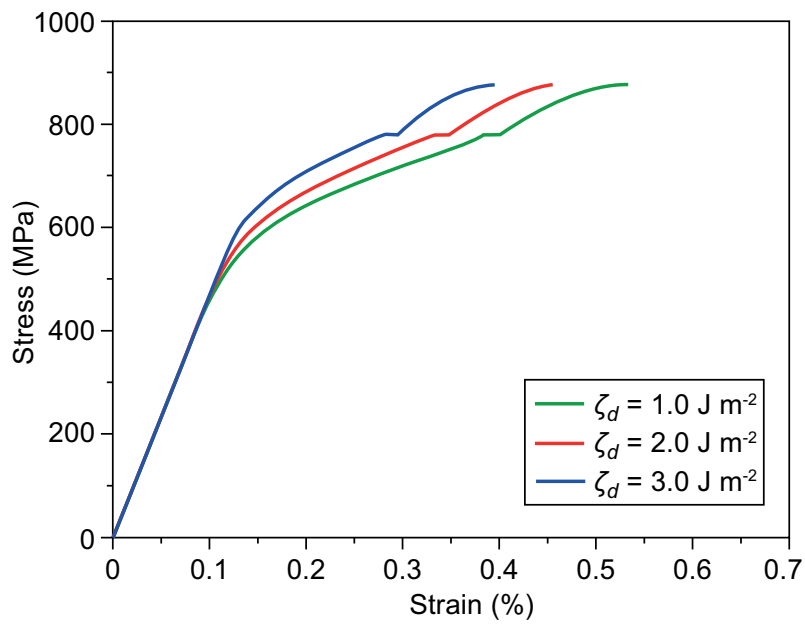

a)
Effect of the interface properties on the fatigue loading/unloading hysteresis loops

The effect of the interface shear stress (i.e., $\tau_{i}=10$, 20 , and $30 \mathrm{MPa}$ ) on the fatigue loading/unloading hysteresis loops and the interface slip of the $\mathrm{SiC} / \mathrm{SiC}$ mini-composite under the peak stress of $\sigma_{\max }=500 \mathrm{MPa}$ is shown in Figure 4. When the interface shear stress increases from $\tau_{i}=10 \mathrm{MPa}$ to $\tau_{i}=30 \mathrm{MPa}$, the fatigue loading/unloading hysteresis loops area, peak and valley strain decrease, and the fatigue loading/unloading hysteresis modulus increases, due to the decrease in the interface slip length. When the interface shear stress increases, the resistance to the interface debonding increases, leading to a decrease in the interface debonding

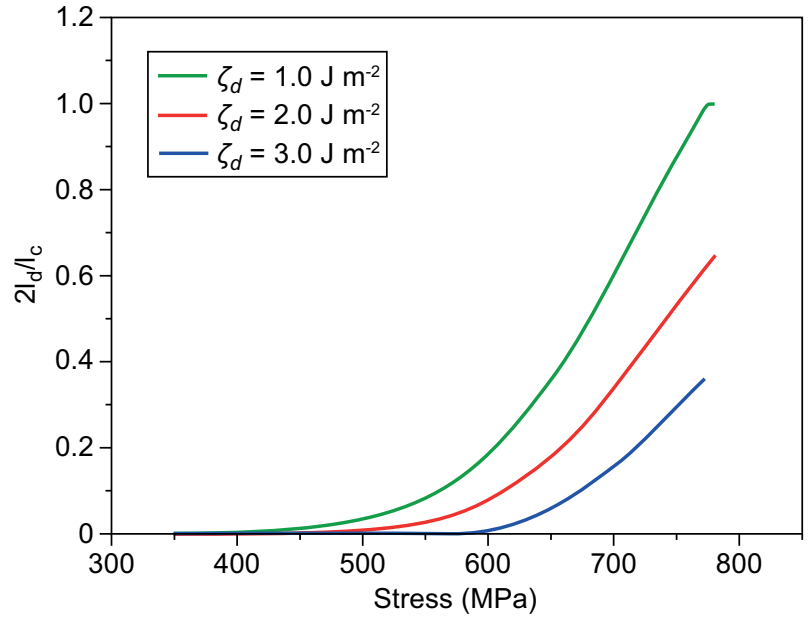

b)

Figure 3. The effect of the interface debonding energy on: a) the tensile stress-strain curves; b) the interface debonding length versus the applied stress curves of the Hi-NicalonTM Type $\mathrm{S} \mathrm{SiC/SiC} \mathrm{mini-composite.}$

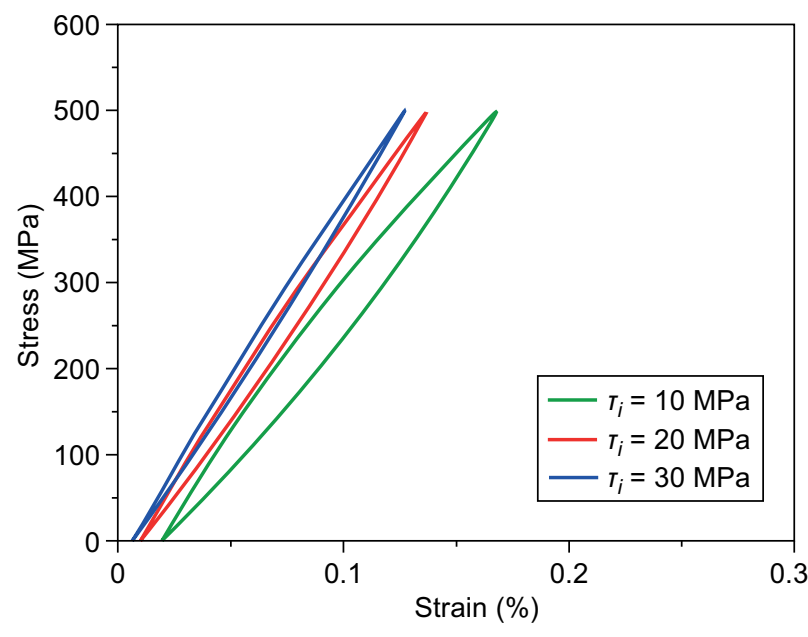

a)

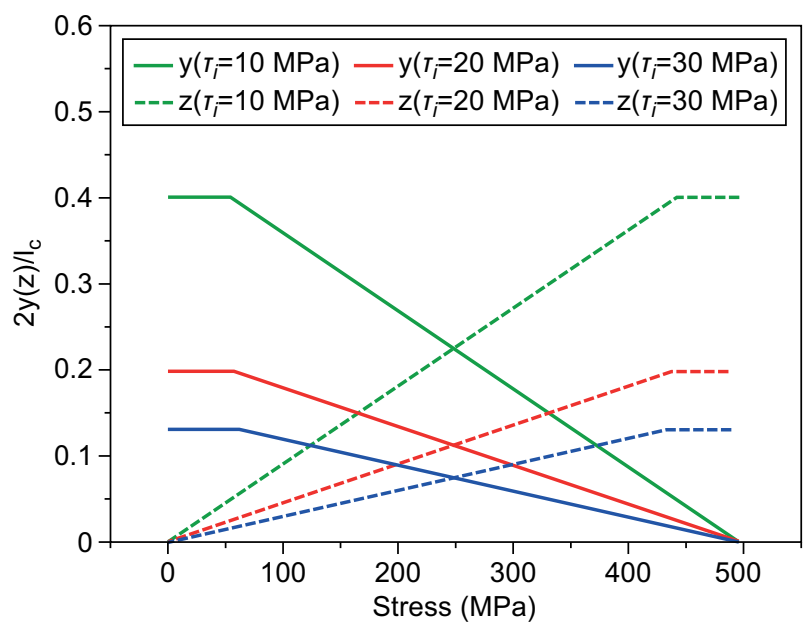

b)

Figure 4. The effect of the interface shear stress on: a) the fatigue loading/unloading hysteresis loops; b) the interface slip lengths versus the applied stress curves of the Hi-NicalonTM Type $\mathrm{S} \mathrm{SiC/SiC} \mathrm{mini-composite.}$ 
and slip length, and a decrease in the area, peak and valley strain of the fatigue loading/unloading hysteresis loops. Under the peak stress of $\sigma_{\max }=500 \mathrm{MPa}$, the interface slip range decreases from $40 \%$ of the matrix crack spacing at $\tau_{i}=10 \mathrm{MPa}$ to $13 \%$ of the matrix crack spacing at $\tau_{i}=30 \mathrm{MPa}$.

The effect of the interface debonding energy (i.e., $\zeta_{\mathrm{d}}=1,3$, and $5 \mathrm{~J} \cdot \mathrm{m}^{-2}$ ) on the fatigue loading/unloading hysteresis loops and the interface slip of the $\mathrm{SiC} / \mathrm{SiC}$ mini-composite under the peak stress of $\sigma_{\max }=800 \mathrm{MPa}$ is shown in Figure 5. When the interface debonding energy increases from $\zeta_{\mathrm{d}}=1 \mathrm{~J} \cdot \mathrm{m}^{-2}$ to $\zeta_{\mathrm{d}}=5 \mathrm{~J} \cdot \mathrm{m}^{-2}$, the fatigue loading/unloading hysteresis loops area, peak and valley strain decrease, and the fatigue hysteresis modulus increases, due to the decrease in the interface slip length. When the interface debonding energy increases, the energy needed for the interface debonding increases, leading to a decrease in the interface debonding length, and a decrease in the area, peak and valley strain of the fatigue loading/unloading hysteresis loops. Under the peak stress of $\sigma_{\max }=800 \mathrm{MPa}$, the interface slip range decreases from $38 \%$ of the matrix crack spacing at $\zeta_{\mathrm{d}}=1 \mathrm{~J} \cdot \mathrm{m}^{-2}$ to $20 \%$ of the matrix crack spacing at $\zeta_{\mathrm{d}}=5 \mathrm{~J} \cdot \mathrm{m}^{-2}$.

\section{EXPERIMENTAL}

Sauder et al. [30] performed investigations on the effect of the tensile and cyclic loading/unloading tensile behaviour of $\mathrm{SiC} / \mathrm{SiC}$ mini-composites with different interface properties. The material properties of the Hi-Nicalon $^{\mathrm{TM}}$ and Tyranno ${ }^{\mathrm{TM}} \mathrm{SiC} / \mathrm{SiC}$ mini-composites are listed in Table 1. The tensile nonlinear strain, matrix cracking evolution, fatigue loading/unloading hysteresis loops, and the interface debonding and slip of HiNicalon $^{\mathrm{TM}}$ and Tyranno ${ }^{\mathrm{TM}} \mathrm{SiC} / \mathrm{SiC}$ minicomposites are predicted considering the different interface properties.

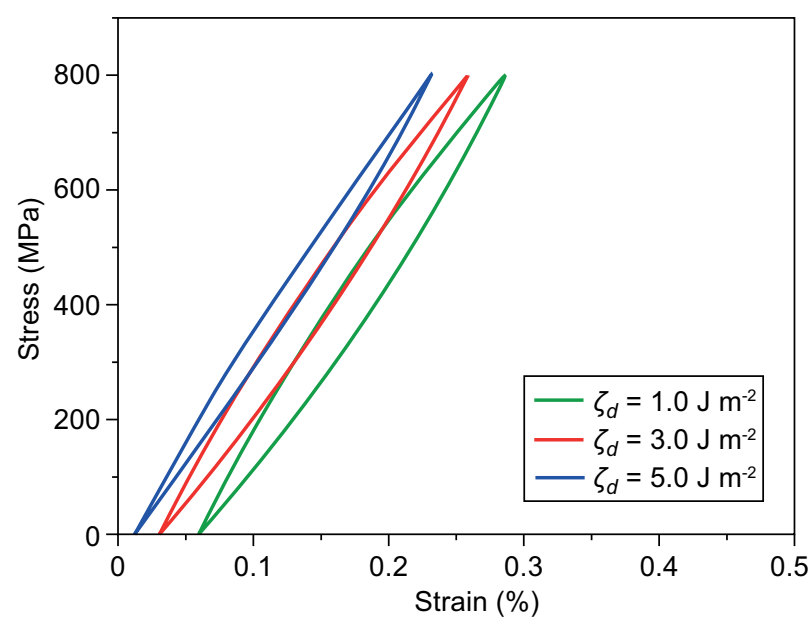

a)

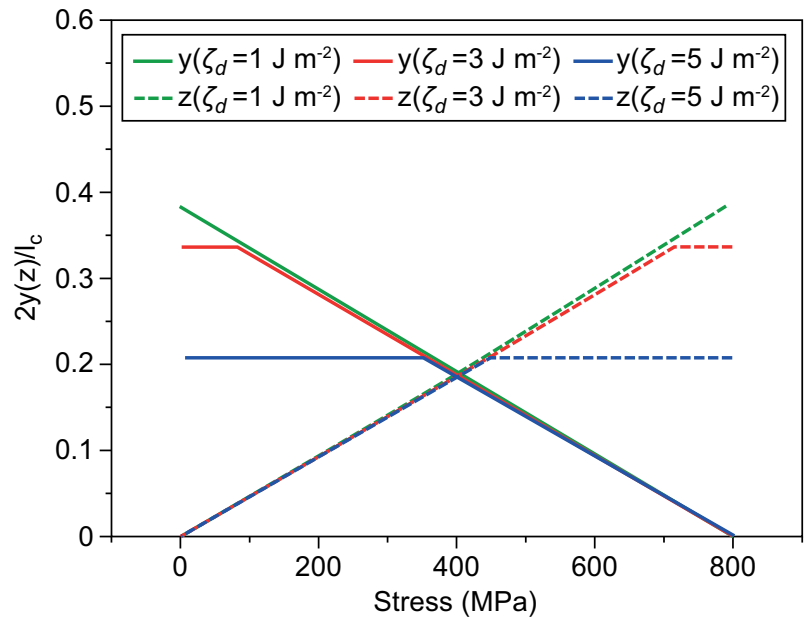

b)

Figure 5. The effect of the interface debonding energy on: a) the fatigue loading/unloading hysteresis loops; d) the interface slip lengths versus the applied stress curves of the Hi-NicalonTM Type S SiC/SiC mini-composite.

Table 1. The material properties of the unidirectional $\mathrm{SiC} / \mathrm{SiC}$ mini-composites.

\begin{tabular}{|c|c|c|c|c|}
\hline Items & $\begin{array}{c}\text { Type A Hi-Nicalon }^{\mathrm{TM}} \\
\text { S SiC/SiC }\end{array}$ & $\begin{array}{c}\text { Type B Hi-Nicalon }{ }^{\mathrm{TM}} \\
\text { S SiC/SiC }\end{array}$ & $\begin{array}{c}\text { Type C Hi-Nicalon }{ }^{\mathrm{TM}} \\
\text { S SiC/SiC }\end{array}$ & $\begin{array}{c}\text { Tyranno }^{\mathrm{TM}} \mathrm{SA} 3 \\
\mathrm{SiC} / \mathrm{SiC}\end{array}$ \\
\hline Interphase & $\begin{array}{c}\text { PyC } \\
(150 \mathrm{~nm})\end{array}$ & $\begin{array}{c}\mathrm{PyC} / \mathrm{SiC} / \mathrm{PyC} / \mathrm{SiC} / \mathrm{PyC} \\
(150 \mathrm{~nm})\end{array}$ & $\begin{array}{c}\mathrm{PyC} \\
(30 \mathrm{~nm})\end{array}$ & $\begin{array}{c}\text { PyC } \\
(150 \mathrm{~nm})\end{array}$ \\
\hline$r_{\mathrm{f}}(\mu \mathrm{m})$ & 6.5 & 6.5 & 6.5 & 3.5 \\
\hline$V_{\mathrm{f}}(\%)$ & 46 & 44 & 40 & 43 \\
\hline$E_{\mathrm{f}}(\mathrm{GPa})$ & 372 & 372 & 372 & 387 \\
\hline$E_{\mathrm{m}}(\mathrm{GPa})$ & 400 & 550 & 550 & 400 \\
\hline$\alpha_{\mathrm{f}}\left(10^{-6} /{ }^{\circ} \mathrm{C}\right)$ & 3.5 & 4.5 & 4.5 & 4 \\
\hline$\alpha_{\mathrm{m}}\left(10^{-6} /{ }^{\circ} \mathrm{C}\right)$ & 4.6 & 4.6 & 4.6 & 4.6 \\
\hline$\tau_{\mathrm{i}}(\mathrm{MPa})$ & 9 & 20 & 10 & 100 \\
\hline$\zeta_{\mathrm{d}}\left(\mathrm{J} \cdot \mathrm{m}^{-2}\right)$ & 0.1 & 0.3 & 0.1 & 0.1 \\
\hline$\sigma_{\mathrm{UTS}}(\mathrm{MPa})$ & 940 & 878 & 860 & 1116 \\
\hline
\end{tabular}


Tensile nonlinear strain and fatigue loading/unloading hysteresis loops of the Type A Hi-Nicalon ${ }^{\mathrm{TM}}$ Type $\mathrm{S}$

$\mathrm{SiC} / \mathrm{SiC}$ mini-composite

The experimental and predicted tensile nonlinear strain, matrix cracking evolution, fatigue loading/unloading hysteresis loops, and interface debonding and sliding of the Type A Hi-Nicalon ${ }^{\mathrm{TM}}$ Type $\mathrm{S} \mathrm{SiC} / \mathrm{SiC}$ minicomposite are shown in Figures 6-9 and Table 2.

Under tensile loading, the tensile stress-strain curve of the $\mathrm{SiC} / \mathrm{SiC}$ mini-composite is predicted using the tensile constitutive model of Equation 4, which exhibits obvious nonlinear behaviour between the first matrix cracking stress of about $\sigma_{\mathrm{mc}}=400 \mathrm{MPa}$ and the saturation matrix cracking stress of about $\sigma_{\text {sat }}=800 \mathrm{MPa}$, and the composite tensile strength is about $\sigma_{\mathrm{UTS}}=940 \mathrm{MPa}$ with the failure strain of $\varepsilon_{\mathrm{f}}=0.64 \%$, as shown in Figure $6 \mathrm{a}$.
Table 2. The tensile nonlinear strain and fatigue loading/unloading hysteresis loops of the Type A Hi-NicalonTM Type S $\mathrm{SiC} / \mathrm{SiC}$ mini-composite.

\begin{tabular}{ccccccc}
\hline \multicolumn{7}{c}{ Tensile } \\
\hline Items & $\begin{array}{c}\sigma_{\mathrm{mc}} \\
(\mathrm{MPa})\end{array}$ & $\begin{array}{c}\sigma_{\text {sat }} \\
(\mathrm{MPa})\end{array}$ & $\begin{array}{c}\sigma_{\mathrm{UTS}} \\
(\mathrm{MPa})\end{array}$ & $\begin{array}{c}\varepsilon_{\mathrm{f}} \\
(\%)\end{array}$ & $\begin{array}{c}\lambda_{\mathrm{mc}} \\
\left(\mathrm{mm}^{-1}\right)\end{array}$ & $\begin{array}{c}\lambda_{\text {sat }} \\
\left(\mathrm{mm}^{-1}\right)\end{array}$ \\
\hline Value & 400 & 800 & 940 & 0.64 & 0.24 & 2.85 \\
\hline \hline \multicolumn{7}{c}{ Fatigue } \\
\hline Items & $\sigma_{\max }$ & $2 l_{\mathrm{d}} / l_{\mathrm{c}}$ & $y(z) / l_{\mathrm{d}}$ & $\begin{array}{c}\sigma_{\mathrm{tr} f \mathrm{fu}} \\
(\mathrm{MPa})\end{array}$ & $\begin{array}{c}\sigma_{\mathrm{tr} \text { ff }} \\
(\mathrm{MPa})\end{array}$ \\
\hline \multirow{4}{*}{ Value } & 500 & 0.56 & 0.86 & - & - \\
& 800 & 1.0 & 1.0 & 400 & 400 \\
& 850 & 1.0 & 1.0 & 467.5 & 382.5 \\
\hline
\end{tabular}

The matrix cracking density is predicted using Equation 3 and increases from $\lambda_{\mathrm{mc}}=0.24 / \mathrm{mm}$ at $\sigma_{\mathrm{mc}}=400 \mathrm{MPa}$ to the saturation matrix cracking density of $\lambda_{\text {sat }}=2.85 \mathrm{~mm}^{-1}$ at $\sigma_{\text {sat }}=800 \mathrm{MPa}$, as shown in Figure $6 \mathrm{~b}$.

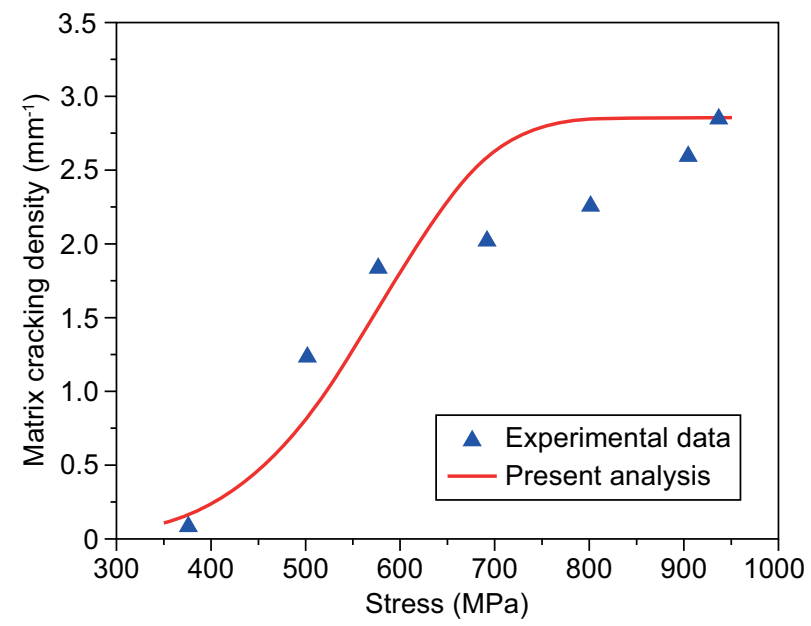

b)

Figure 6. The experimental and predicted tensile stress-strain curves (a) and the experimental and predicted matrix cracking den-sity versus the applied stress curves of the Type A Hi-NicalonTM Type S SiC/SiC mini-composite (b).

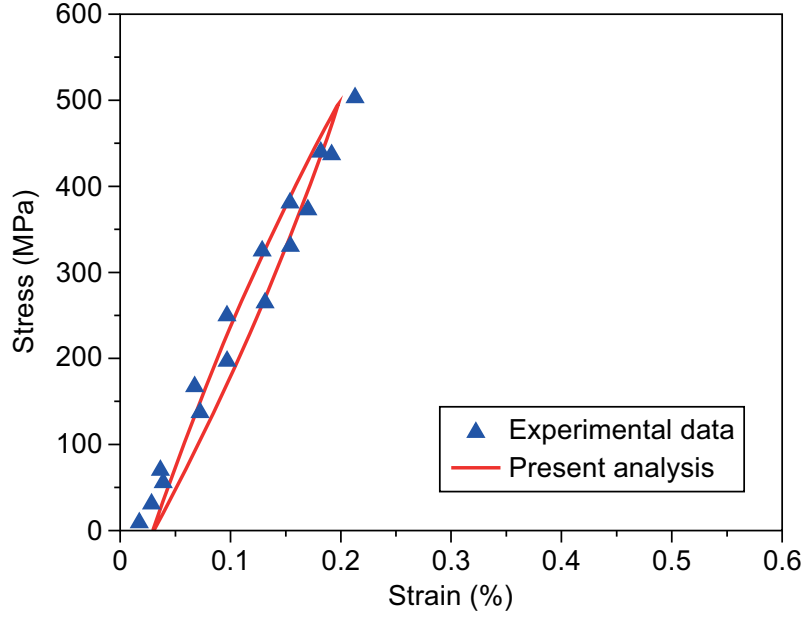

a)

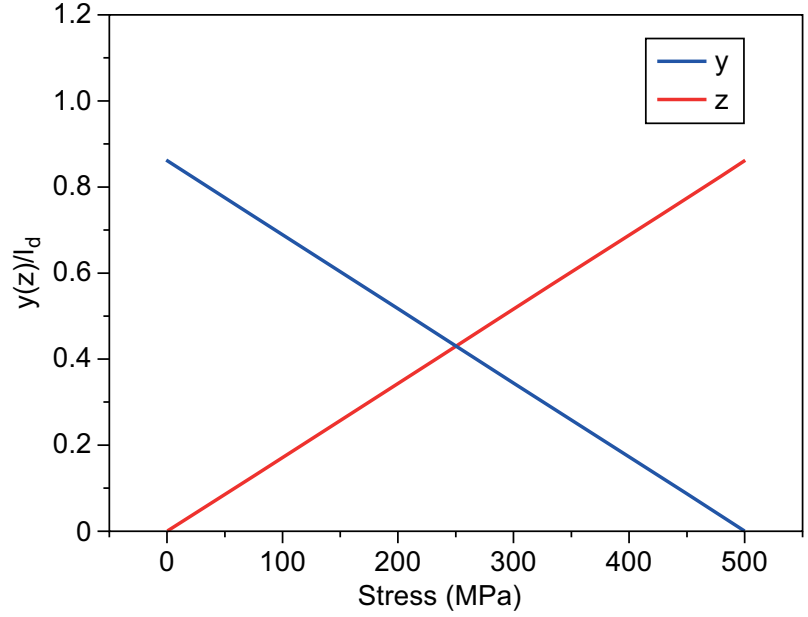

b)

Figure 7. The experimental and predicted fatigue loading/unloading hysteresis loops(a) and the experimental and predicted inter-face slip length versus the applied stress curves of the Type A Hi-NicalonTM Type S SiC/SiC mini-composite under the peak stress of $\sigma_{\text {max }}=500 \mathrm{MPa}(\mathrm{b})$. 
Under fatigue loading/unloading, the interface partially debonds (i.e., $2 l_{\mathrm{d}} / l_{\mathrm{c}}=0.56$ ), and the fibre partially slides relative to the matrix in the interface debonding region (i.e., $y(z) / l_{\mathrm{d}}=0.86$ ) under the peak stress of $\sigma_{\max }=500 \mathrm{MPa}$, and the interface debonding length is determined using Equation 2, and the fatigue loading/ unloading hysteresis loop is predicted by Equations 5 and 6, as shown in Figure 7; and under the peak stress of $\sigma_{\max }=800$, and $850 \mathrm{MPa}$, the fibre/matrix interface completely debonds (i.e., $2 l_{\mathrm{d}} / l_{\mathrm{c}}=1$ ), and the fibre completely slides relative to the matrix at the matrix crack spacing (i.e., $y(z) / l_{\mathrm{d}}=1$ ), and the interface debonding length is determined using Equation 2, and the fatigue loading/unloading hysteresis loop is predicted by Equations 7 and 8, as shown in Figures 8 and 9.

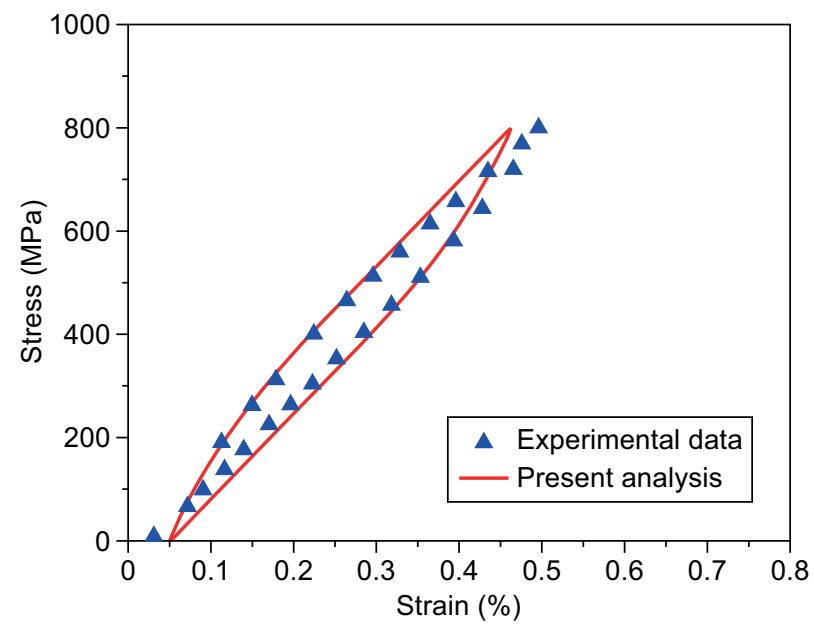

a)
Table 3. The tensile nonlinear strain and fatigue loading/unloading hysteresis loops of the Type B Hi-NicalonTM Type S $\mathrm{SiC} / \mathrm{SiC}$ mini-composite.

\begin{tabular}{lcccccc}
\hline \multicolumn{6}{c}{ Tensile } \\
\hline Items & $\begin{array}{c}\sigma_{\mathrm{mc}} \\
(\mathrm{MPa})\end{array}$ & $\begin{array}{c}\sigma_{\text {sat }} \\
(\mathrm{MPa})\end{array}$ & $\begin{array}{c}\sigma_{\mathrm{UTS}} \\
(\mathrm{MPa})\end{array}$ & $\begin{array}{c}\varepsilon_{\mathrm{f}} \\
(\%)\end{array}$ & $\begin{array}{c}\lambda_{\mathrm{mc}} \\
\left(\mathrm{mm}^{-1}\right)\end{array}$ & $\begin{array}{c}\lambda_{\text {sat }} \\
\left(\mathrm{mm}^{-1}\right)\end{array}$ \\
\hline Value & 350 & 780 & 878 & 0.54 & 1.1 & 4.5 \\
\hline \hline \multicolumn{7}{c}{ Fatigue } \\
\hline Items & $\sigma_{\max }$ & $2 l_{\mathrm{d}} / l_{\mathrm{c}}$ & $y(z) / l_{\mathrm{d}}$ & $\sigma_{\mathrm{tr} f \mathrm{fu}}$ & $\begin{array}{c}\sigma_{\text {tr fr }} \\
(\mathrm{MPa})\end{array}$ & $(\mathrm{MPa})$ \\
\hline & 632 & 0.32 & 0.88 & - & - \\
& 699 & 0.6 & 0.84 & - & - \\
Value & 724 & 1.0 & 0.55 & - & - \\
& 778 & 1.0 & 0.79 & - & - \\
& 837 & 1.0 & 1.0 & 41.8 & 795.2 \\
& 878 & 1.0 & 1.0 & 175.6 & 702.4 \\
\hline & & & & &
\end{tabular}

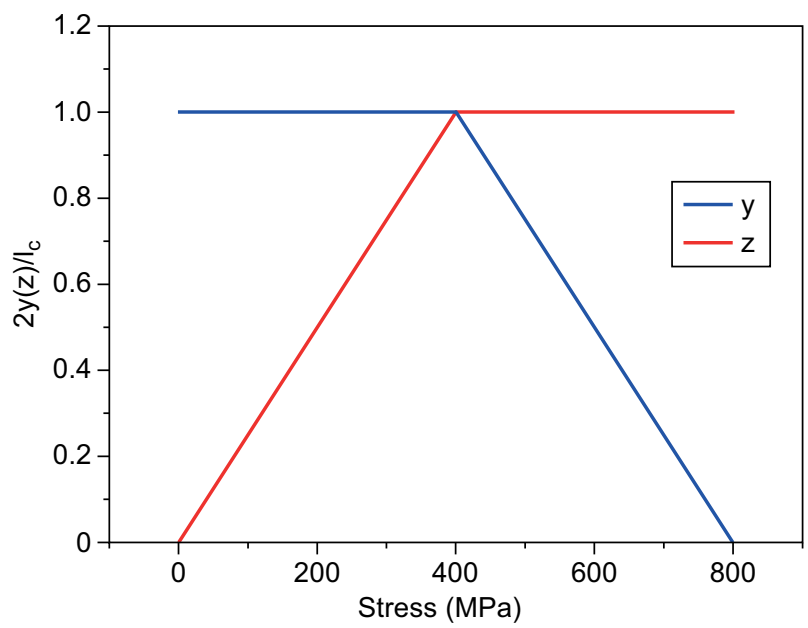

b)

Figure 8. The experimental and predicted fatigue loading/unloading hysteresis loops (a) and the experimental and predicted inter-face slip length versus the applied stress curves of the Type A Hi-NicalonTM Type S SiC/SiC mini-composite under the peak stress of $\sigma_{\max }=800 \mathrm{MPa}(\mathrm{b})$.

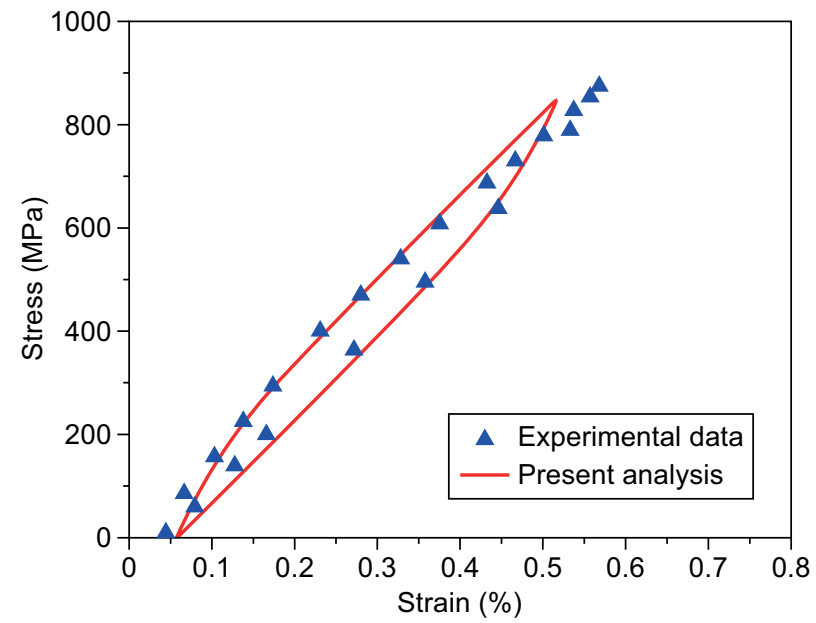

a)

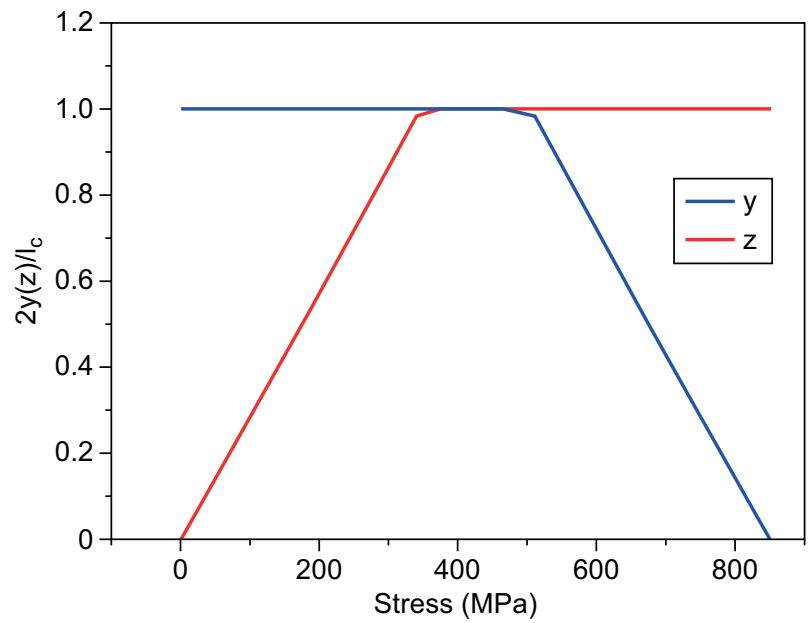

b)

Figure 9. The experimental and predicted fatigue loading/unloading hysteresis loops (a) and the experimental and predicted inter-face slip lengths versus the applied stress curves of the Type A Hi-NicalonTM Type S SiC/SiC mini-composite under the peak stress of $\sigma_{\text {max }}=850 \mathrm{MPa}(\mathrm{b})$. 
Tensile nonlinear strain and fatigue loading/unloading hysteresis loops of the Type B Hi-Nicalon ${ }^{\mathrm{TM}}$ Type $\mathrm{S}$

$\mathrm{SiC} / \mathrm{SiC}$ mini-composite

For the Type B Hi-Nicalon ${ }^{\mathrm{TM}}$ Type $\mathrm{S} \mathrm{SiC/SiC} \mathrm{mi-}$ ni-composite, the experimental and predicted tensile nonlinear strain, and matrix cracking evolution are shown in Figure 10 and Table 3. The tensile stress-strain curve is predicted using the tensile constitutive model of Equation 4, which exhibits obvious nonlinear behaviour between the first matrix cracking stress of $\sigma_{\mathrm{mc}}=350 \mathrm{MPa}$ and the saturation matrix cracking stress of $\sigma_{\text {sat }}=780 \mathrm{MPa}$, and the composite tensile strength is about $\sigma_{\mathrm{UTS}}=878 \mathrm{MPa}$ with the failure strain of $\varepsilon_{\mathrm{f}}=0.54 \%$. The matrix cracking density is predicted using Equation 3 and increases from $\lambda_{\mathrm{mc}}=1.1 \mathrm{~mm}^{-1}$ at $\sigma_{\mathrm{mc}}=600 \mathrm{MPa}$ to $\lambda_{\text {sat }}=4.5 \mathrm{~mm}^{-1}$ at $\sigma_{\text {sat }}=875 \mathrm{MPa}$.

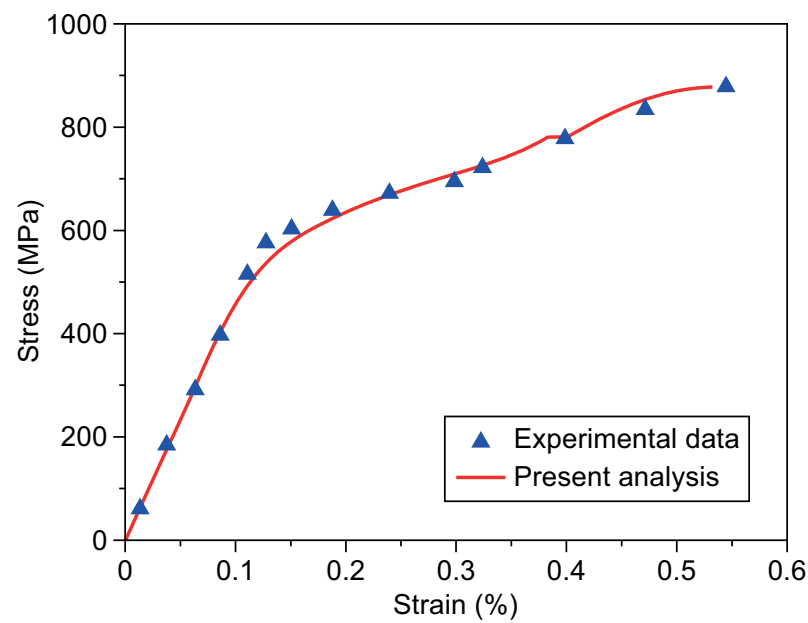

a)
The experimental and predicted fatigue loading/unloading hysteresis loops and interface slip under the peak stresses of $\sigma_{\max }=632,669,724,778,837$, and $878 \mathrm{MPa}$ are shown in Figures 11-16 and Table 3. Upon unloading and reloading, the interface partially debonds and the fibre partially slides relative to the matrix under the peak stresses of $\sigma_{\max }=632$ and $669 \mathrm{MPa}$, and the interface debonding length is determined using Equation 2, and the fatigue loading/unloading hysteresis loop is predicted by Equations 5 and 6; the interface completely debonds and the fibre partially slides relative to the matrix under the peak stresses of $\sigma_{\max }=724$ and $778 \mathrm{MPa}$, and the interface debonding length is determined using Equation 2, and the fatigue loading/unloading hysteresis loop is predicted by Equations 7 and 8; and the interface completely debonds and the fibre completely slides relative to the matrix under the peak stresses of $\sigma_{\max }=$ $=837$ and $878 \mathrm{MPa}$, and the interface debonding length

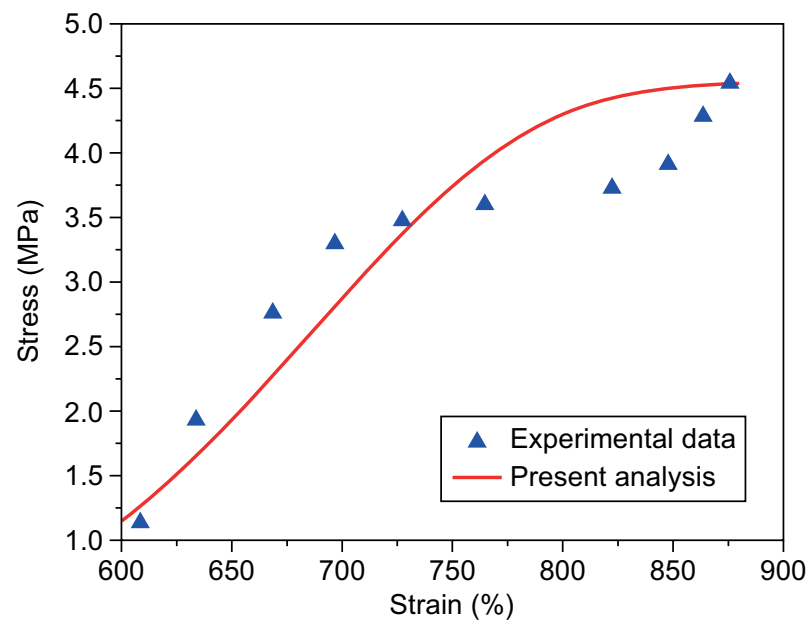

b)

Figure 10. The experimental and predicted tensile stress-strain curves (a) and the experimental and predicted matrix cracking density versus the applied stress curves of the Type B Hi-NicalonTM Type S SiC/SiC mini-composite (b).

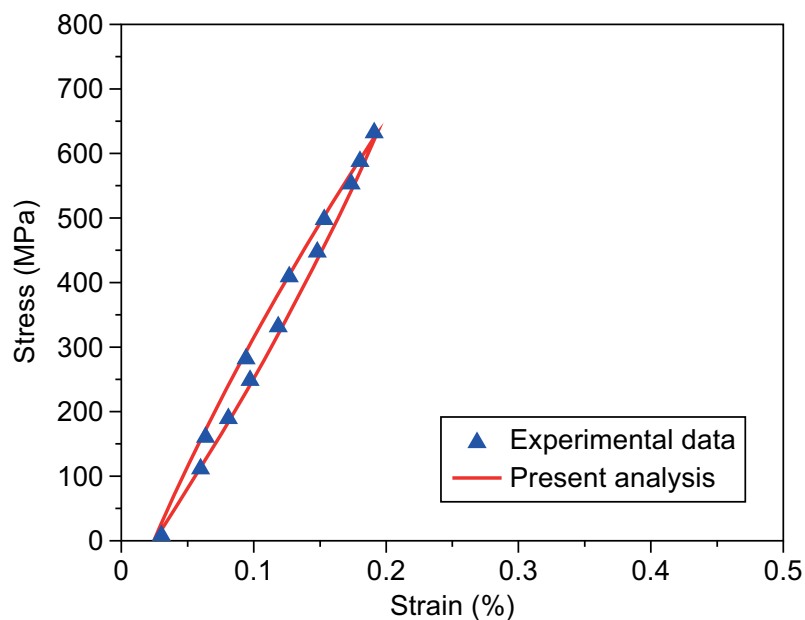

a)

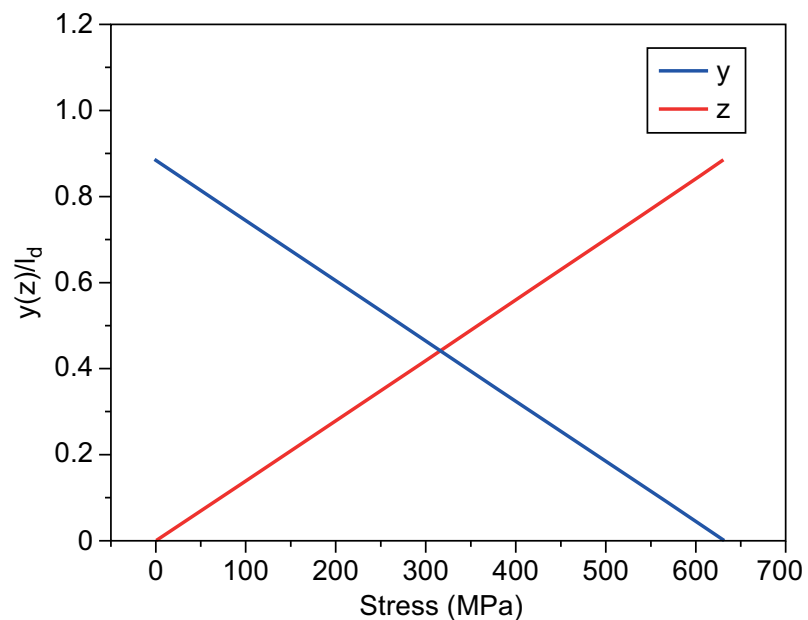

b)

Figure 11. The experimental and predicted fatigue loading/unloading hysteresis loops (a) and the experimental and predicted interface slip length versus the applied stress curves of the Type B Hi-NicalonTM Type S SiC/SiC mini-composite under the peak stress of $\sigma_{\text {max }}=632 \mathrm{MPa}$ (b). 
is determined using Equation 2, and the fatigue loading/ unloading hysteresis loop is predicted by Equations 7 and 8 .

Tensile nonlinear strain and fatigue loading/unloading hysteresis loops of the Type C Hi-Nicalon ${ }^{\mathrm{TM}}$ Type $\mathrm{S}$

$\mathrm{SiC} / \mathrm{SiC}$ mini-composite

For the Type $\mathrm{C}$ Hi-Nicalon ${ }^{\mathrm{TM}}$ Type $\mathrm{S} \mathrm{SiC} / \mathrm{SiC}$ minicomposite, the tensile stress-strain curve is predicted using the tensile constitutive model of Equation 4 . The nonlinear tensile strain starts from the first matrix cracking stress of $\sigma_{\mathrm{mc}}=300 \mathrm{MPa}$, and the composite tensile strength is about $\sigma_{\mathrm{UTS}}=860 \mathrm{MPa}$ with the failure strain of $\varepsilon_{\mathrm{f}}=0.62 \%$. The matrix cracking density is predicted using Equation 3 and increases from $\lambda_{\mathrm{mc}}=0.02 \mathrm{~mm}^{-1}$ at $\sigma_{\mathrm{mc}}=300 \mathrm{MPa}$ to $\lambda=5.8 / \mathrm{mm}$ at $\sigma_{\text {sat }}=850 \mathrm{MPa}$, as
Table 4. The tensile nonlinear strain and fatigue loading/unloading hysteresis loops of the Type C Hi-NicalonTM Type S $\mathrm{SiC} / \mathrm{SiC}$ mini-composite.

\begin{tabular}{lcccccc}
\hline \multicolumn{7}{c}{ Tensile } \\
\hline Items & $\begin{array}{c}\sigma_{\mathrm{mc}} \\
(\mathrm{MPa})\end{array}$ & $\begin{array}{c}\sigma_{\text {sat }} \\
(\mathrm{MPa})\end{array}$ & $\begin{array}{c}\sigma_{\mathrm{UTS}} \\
(\mathrm{MPa})\end{array}$ & $\begin{array}{c}\varepsilon_{\mathrm{f}} \\
(\%)\end{array}$ & $\begin{array}{c}\lambda_{\mathrm{mc}} \\
\left(\mathrm{mm}^{-1}\right)\end{array}$ & $\begin{array}{c}\lambda_{\text {sat }} \\
\left(\mathrm{mm}^{-1}\right)\end{array}$ \\
\hline Value & 300 & 850 & 860 & 0.62 & 0.02 & 5.8 \\
\hline \hline \multicolumn{7}{c}{ Fatigue } \\
\hline Items & $\sigma_{\max }$ & $2 l_{\mathrm{d}} / l_{\mathrm{c}}$ & $y(z) / l_{\mathrm{d}}$ & $\begin{array}{c}\sigma_{\text {tr fu }} \\
(\mathrm{MPa})\end{array}$ & $\begin{array}{c}\sigma_{\text {tr fr }} \\
(\mathrm{MPa})\end{array}$ \\
\hline \multirow{4}{*}{ Value } & 485 & 1.0 & 0.824 & - & - \\
& 569 & 1.0 & 1.0 & 28.5 & 540.5 \\
& 662 & 1.0 & 1.0 & 264.8 & 397.2 \\
& 743 & 1.0 & 1.0 & 334.3 & 408.7 \\
\hline
\end{tabular}

shown in Figure 17 and Table 4 . When the fatigue peak stress increases from $\sigma_{\max }=485 \mathrm{MPa}$ to $\sigma_{\max }=743 \mathrm{MPa}$, the interface completely debonds and the fibre sliding

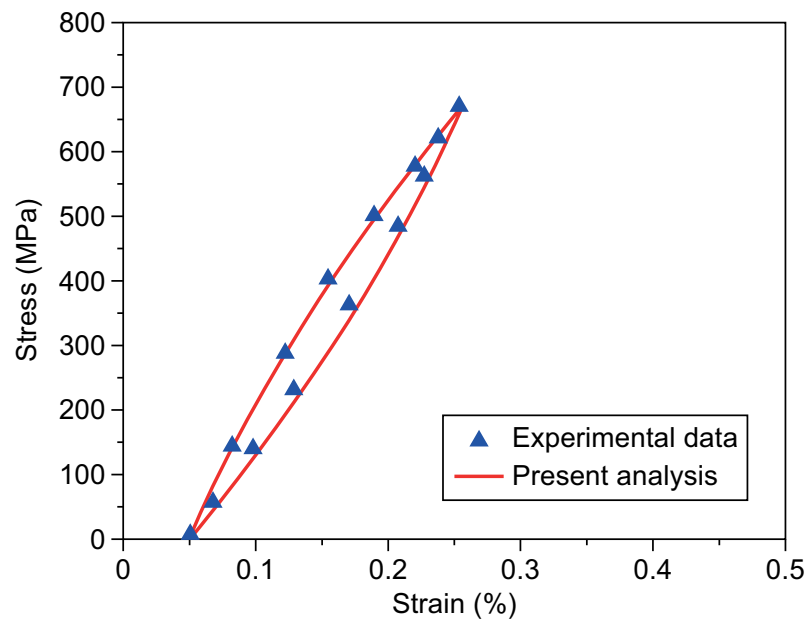

a)

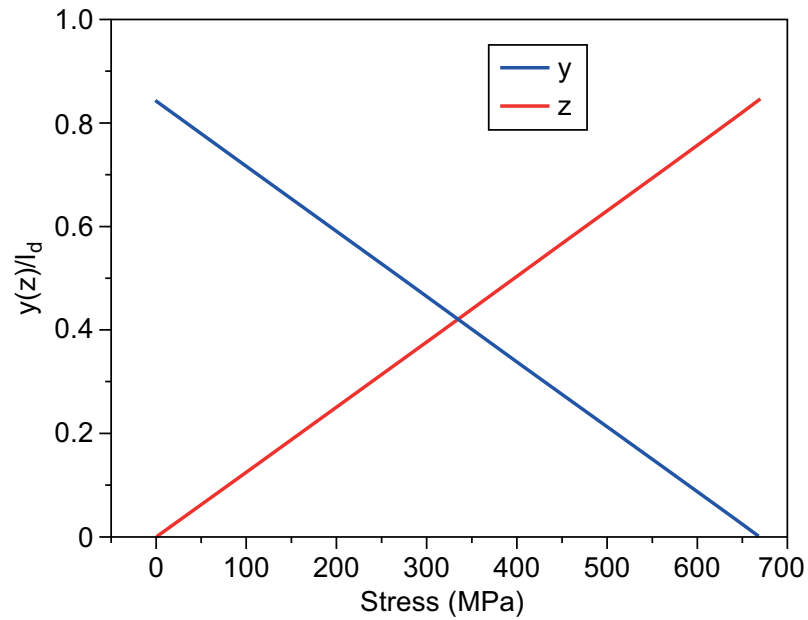

b)

Figure 12. The experimental and predicted fatigue loading/unloading hysteresis loops (a) and the experimental and predicted interface slip length versus the applied stress curves of the Type B Hi-NicalonTM Type S SiC/SiC mini-composite under the peak stress of $\sigma_{\max }=669 \mathrm{MPa}$ (b).

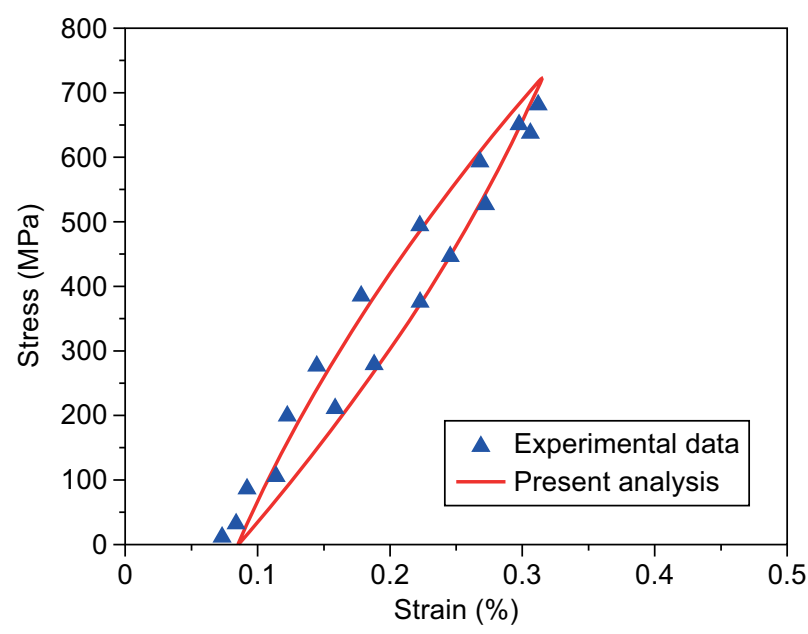

a)

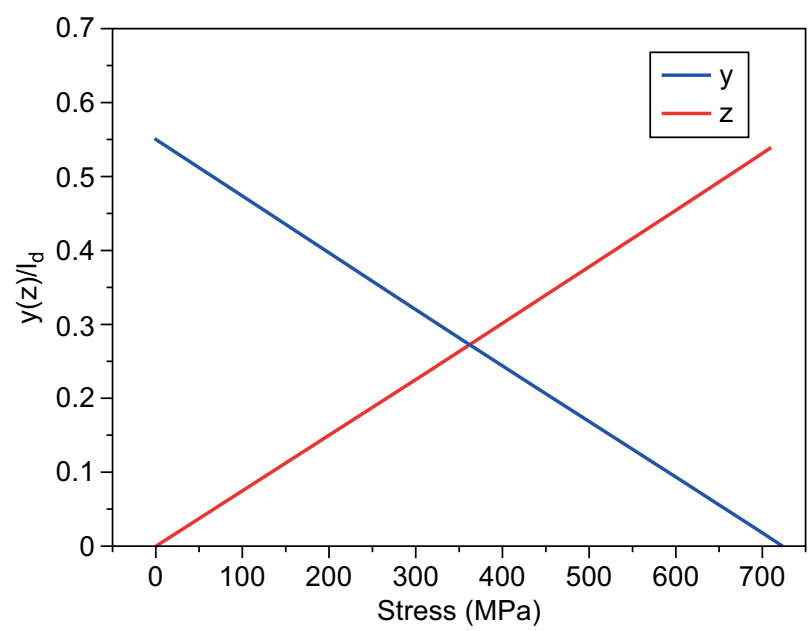

b)

Figure 13. The experimental and predicted fatigue loading/unloading hysteresis loops (a) and the experimental and predicted interface slip length versus the applied stress curves of the Type B Hi-NicalonTM Type S SiC/SiC mini-composite under the peak stress of $\sigma_{\max }=724 \mathrm{MPa}(\mathrm{b})$. 
range increases from a partial slip (i.e., $\left.y(z) / l_{\mathrm{d}}<1\right)$ to a complete slip (i.e., $y(z) / l_{\mathrm{d}}=1$ ), and the interface debonding length is determined using Equation 2, and the fatigue loading/unloading hysteresis loop is predicted by Equations 5 and 6, as shown in Figures 18-21 and Table 4.

Tensile nonlinear strain and fatigue loading/unloading hysteresis loops of the Tyranno ${ }^{\mathrm{TM}} \mathrm{SA} 3 \mathrm{SiC} / \mathrm{SiC}$ mini-composite

For the Tyranno ${ }^{\mathrm{TM}} \mathrm{SA} 3 \mathrm{SiC} / \mathrm{SiC}$ mini-composite, the tensile nonlinear strain is predicted using the tensile constitutive model of Equation 4 and evolves from the first matrix cracking stress of $\sigma_{\mathrm{mc}}=600 \mathrm{MPa}$ to the saturation matrix cracking stress of $\sigma_{\text {sat }}=1000 \mathrm{MPa}$, and the corresponding matrix cracking density is predicted

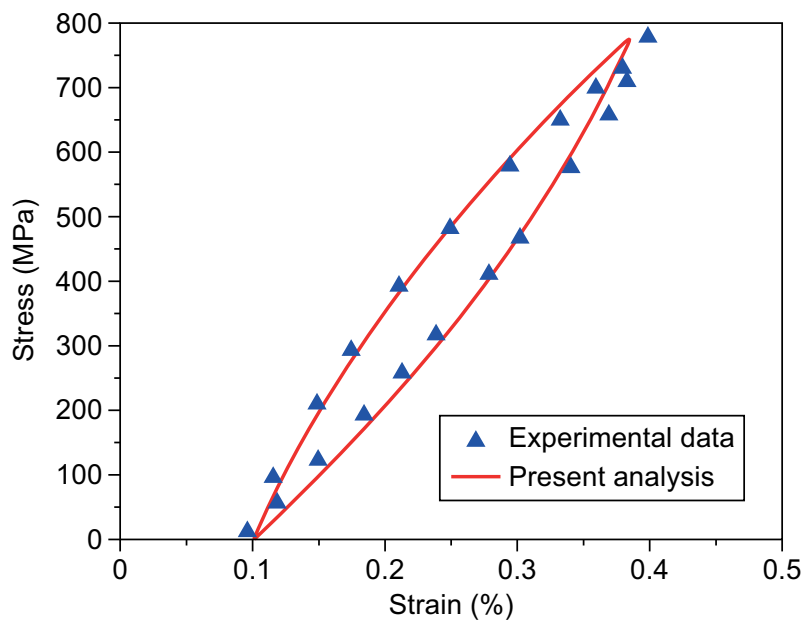

a)
Table 5. The tensile nonlinear strain and fatigue loading/unloading hysteresis loops of the TyrannoTM SA3 SiC/SiC minicomposite.

\begin{tabular}{lcccccc}
\hline \multicolumn{7}{c}{ Tensile } \\
\hline Items & $\begin{array}{c}\sigma_{\mathrm{mc}} \\
(\mathrm{MPa})\end{array}$ & $\begin{array}{c}\sigma_{\text {sat }} \\
(\mathrm{MPa})\end{array}$ & $\begin{array}{c}\sigma_{\mathrm{UTS}} \\
(\mathrm{MPa})\end{array}$ & $\begin{array}{c}\varepsilon_{\mathrm{f}} \\
(\%)\end{array}$ & $\begin{array}{c}\lambda_{\mathrm{mc}} \\
\left(\mathrm{mm}^{-1}\right)\end{array}$ & $\begin{array}{c}\lambda_{\text {sat }} \\
\left(\mathrm{mm}^{-1}\right)\end{array}$ \\
\hline Value & 600 & 1000 & 1116 & 0.58 & 1.6 & 25 \\
\hline \hline \multicolumn{7}{c}{ Fatigue } \\
\hline Items & $\begin{array}{c}\sigma_{\max } \\
(\mathrm{MPa})\end{array}$ & $2 l_{\mathrm{d}} / l_{\mathrm{c}}$ & $y(z) / l_{\mathrm{d}}$ & $\begin{array}{c}\sigma_{\mathrm{tr} \text { fu }} \\
(\mathrm{MPa})\end{array}$ & $\begin{array}{c}\sigma_{\mathrm{tr} \text { fr }} \\
(\mathrm{MPa})\end{array}$ \\
\hline \multirow{3}{*}{ Value } & 884 & 0.27 & 0.83 & - & - \\
& 933 & 0.45 & 0.78 & - & - \\
& 985 & 0.63 & 0.73 & - & - \\
\hline
\end{tabular}

using Equation 3 and evolves from $\lambda_{\mathrm{mc}}=1.6 \mathrm{~mm}^{-1}$ to $\lambda_{\text {sat }}=25 \mathrm{~mm}^{-1}$, and the composite tensile strength is about $\sigma_{\mathrm{UTS}}=1116 \mathrm{MPa}$ with the failure strain of $\varepsilon_{f}=0.58 \%$, as shown in Figure 22 and Table 5. Under the peak

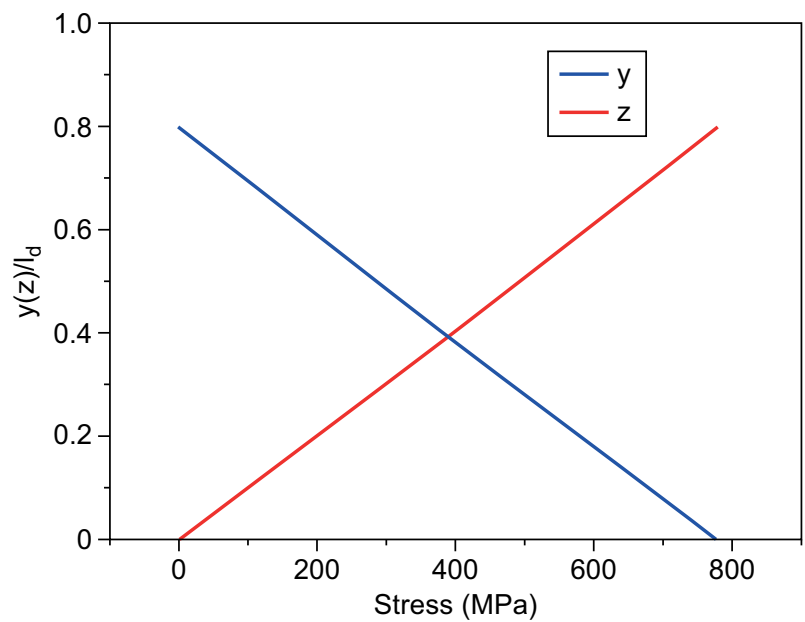

b)

Figure 14. The experimental and predicted fatigue loading/unloading hysteresis loops (a) and the experimental and predicted interface slip length versus the applied stress curves of the Type B Hi-NicalonTM Type S SiC/SiC mini-composite under the peak stress of $\sigma_{\max }=778 \mathrm{MPa}$ (b).

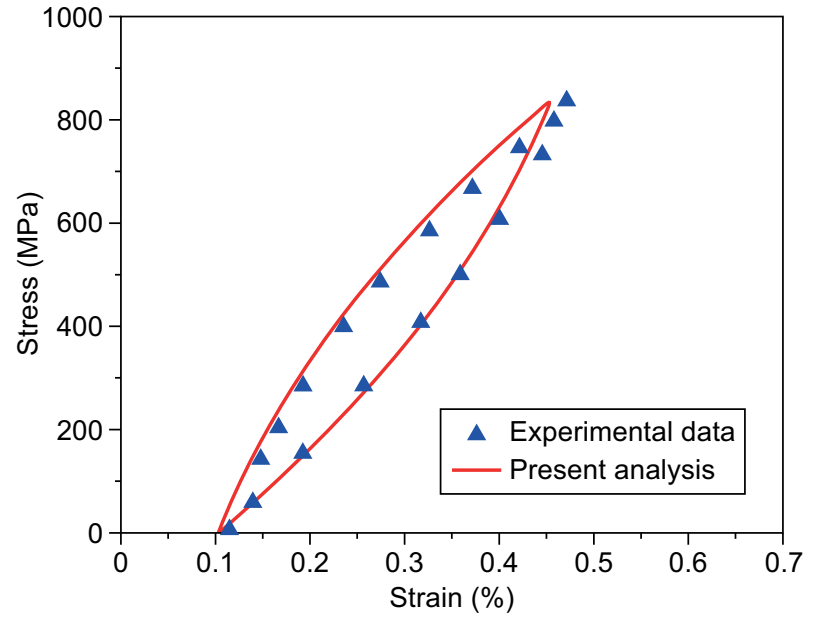

a)

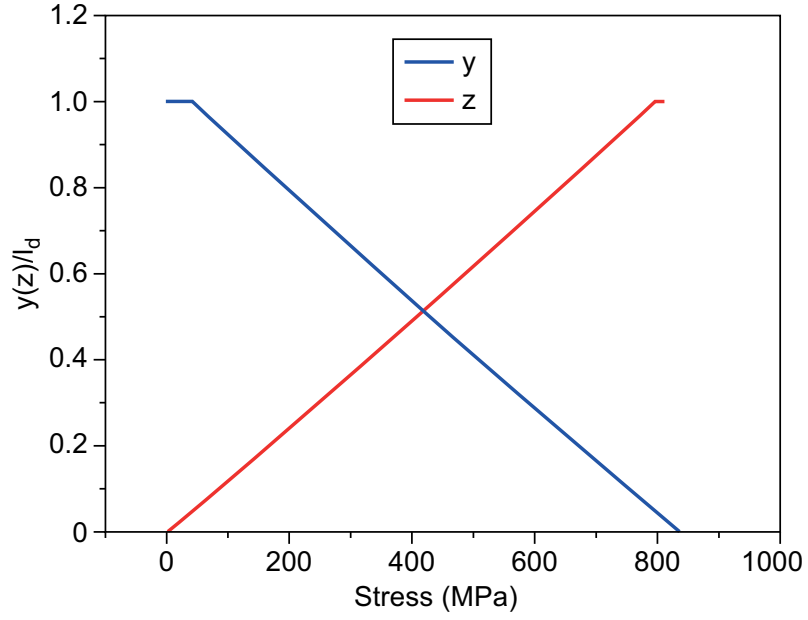

b)

Figure 15. The experimental and predicted fatigue loading/unloading hysteresis loops (a) and the experimental and predicted interface slip length versus the applied stress curves of the Type B Hi-NicalonTM Type S SiC/SiC mini-composite under the peak stress of $\sigma_{\max }=837 \mathrm{MPa}(\mathrm{b})$. 
stresses of $\sigma_{\max }=884,933$, and $985 \mathrm{MPa}$, the interface debonds partially (i.e., $2 l_{\mathrm{d}} / l_{\mathrm{c}}=0.27,0.45$, and 0.63 ), and the fibre slides partially relative to the matrix (i.e., $y(z) /$ $l_{\mathrm{d}}=0.83,0.78$, and 0.73 ), and the interface debonding length is determined using Equation 2, and the fatigue loading/unloading hysteresis loop is predicted by Equations 5 and 6, as shown in Figures 23-25 and Table 5.

\section{CONCLUSION}

In this paper, the tensilenonlinearstrain and the fatigue loading/unloading hysteresis loops of the long-fibrereinforced unidirectional mini-CMCs were investigated for different interface properties. The nonlinear tensile constitutive model and the fatigue loading/unloading constitutive model were developed considering different damage mechanisms. The relationships between the interface properties, tensile nonlinear strain, and fatigue loading/unloading hysteresis loops were established. The effects of the interface properties on the tensile damage and the fracture, fatigue loading/unloading hysteresis loops area, strain, and modulus were analysed. When the interface shear stress or interface debonding energy increases, the interface debonding length and slip length decrease, leading to a decrease in the tensile damage and failure strain, and the area, peak and residual strain of the fatigue loading/unloading hysteresis loops, and an increase in the fatigue hysteresis modulus. The tensile damage and fracture, and the fatigue loading/unloading hysteresis loops of the Hi-Nicalon ${ }^{\mathrm{TM}}$ and Tyranno ${ }^{\mathrm{TM}}$ $\mathrm{SiC} / \mathrm{SiC}$ mini-composites with the different interface properties were analysed. The experimental matrix cracking evolution, tensile nonlinear strain, and fatigue loading/unloading hysteresis loops were predicted, and related to the interface debonding and slip condition.

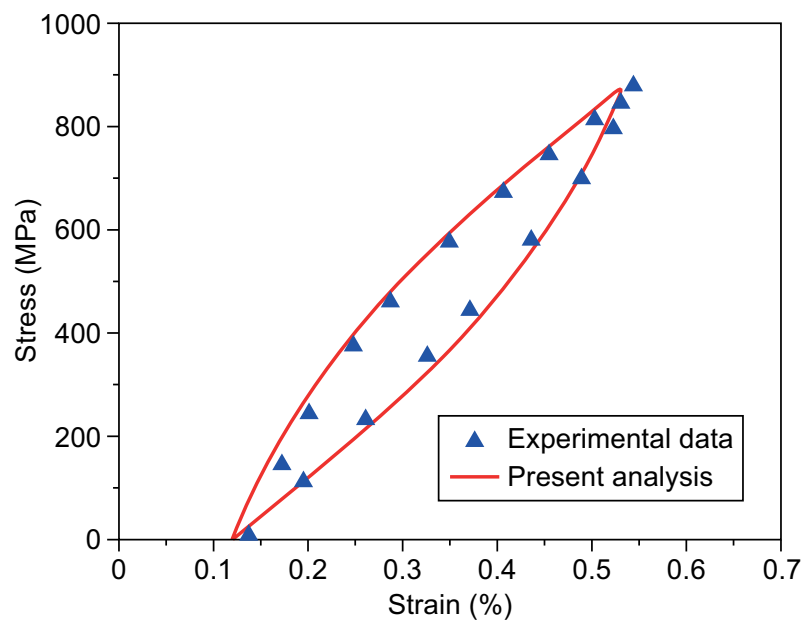

a)

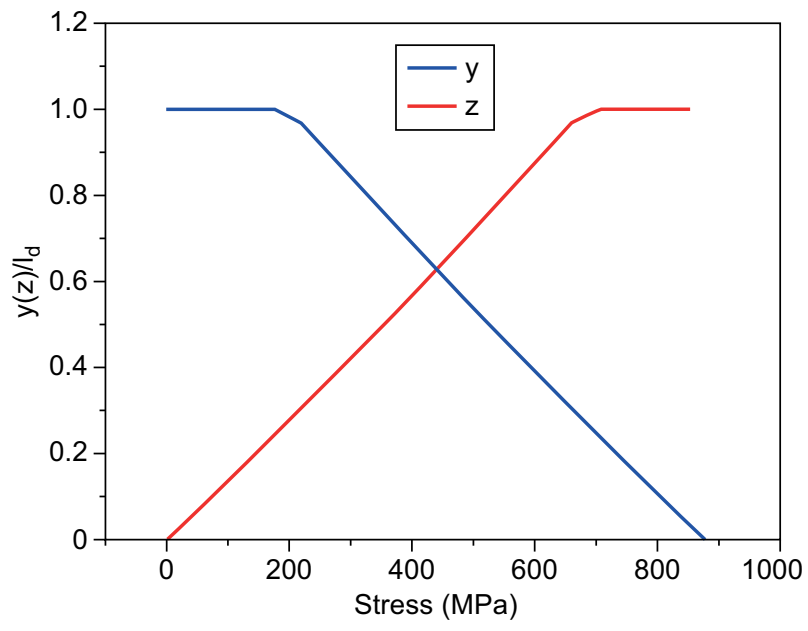

b)

Figure 16. The experimental and predicted fatigue loading/unloading hysteresis loops (a) and the experimental and predicted interface slip length versus the applied stress curves of the Type B Hi-NicalonTM Type S SiC/SiC mini-composite under the peak stress of $\sigma_{\max }=878 \mathrm{MPa}$ (b).

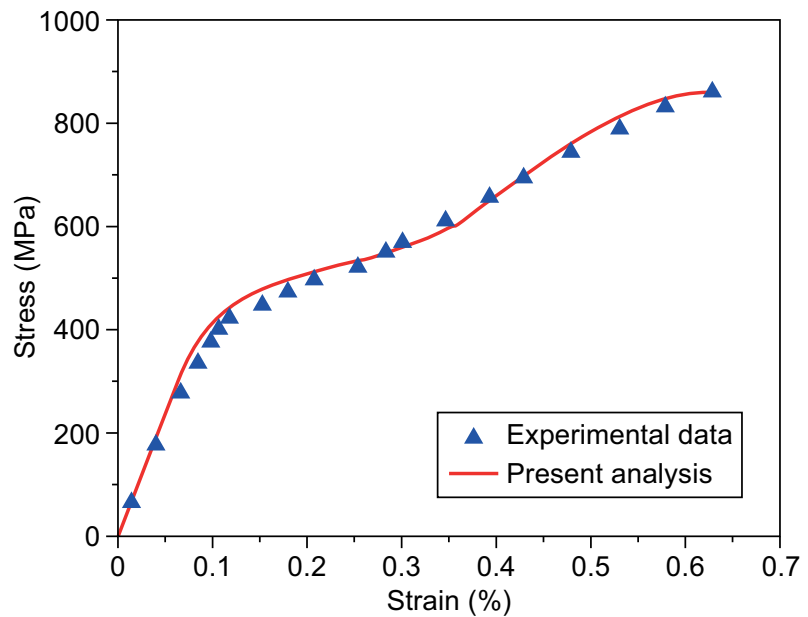

a)

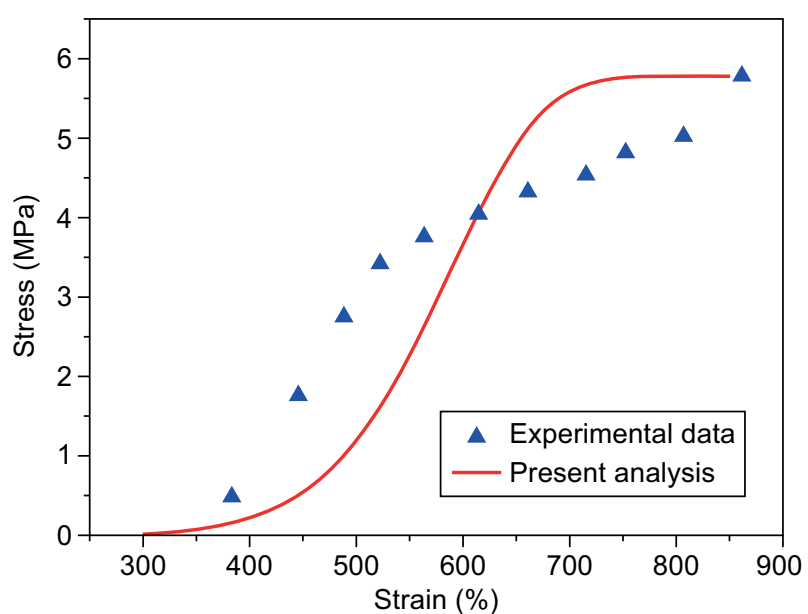

b)

Figure 17. The experimental and predicted tensile stress-strain curves (a) and the experimental and predicted matrix cracking density versus the applied stress curves of the Type C Hi-NicalonTM Type S SiC/SiC mini-composite (b). 


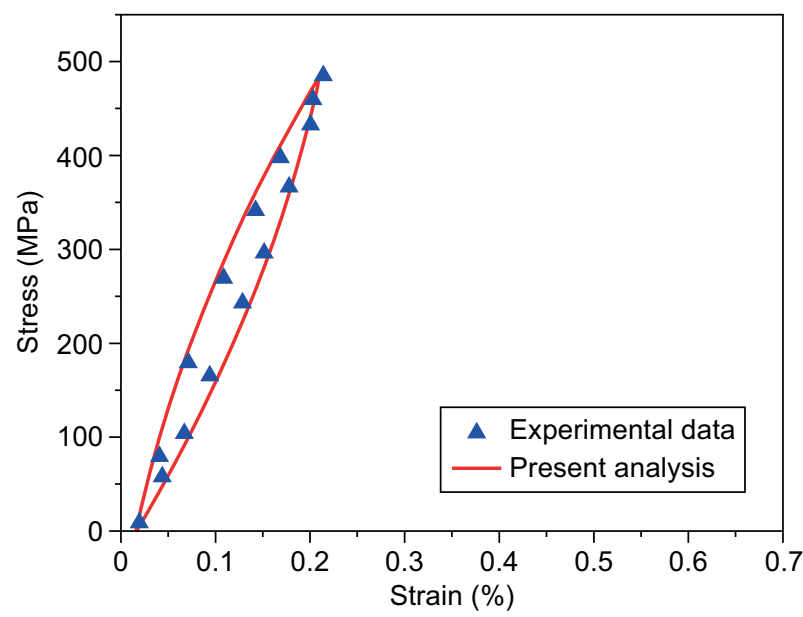

a)

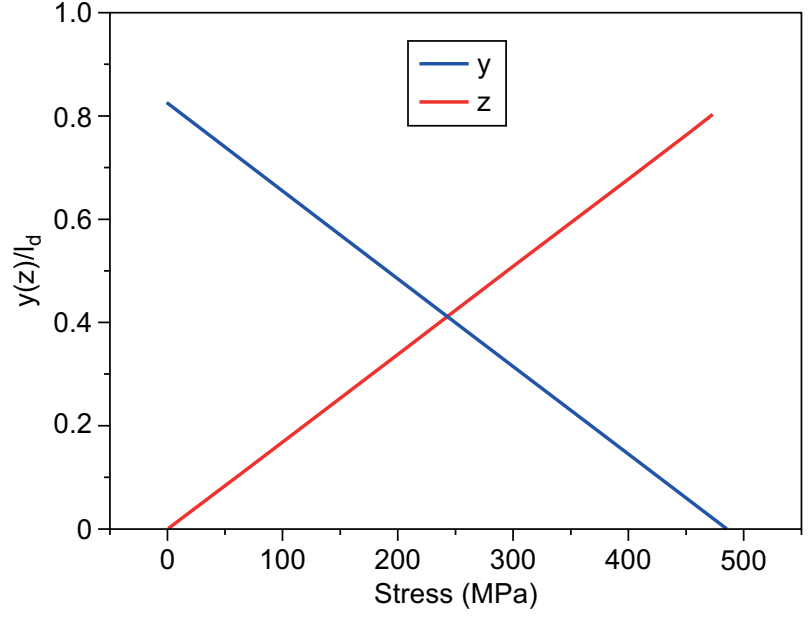

b)

Figure 18. The experimental and predicted hysteresis loops (a) and the experimental and predicted interface slip lengths versus the applied stress curves of the Type C Hi-NicalonTM Type S SiC/SiC mini-composite under the peak stress of $\sigma_{\max }=485 \mathrm{MPa}(\mathrm{b})$.

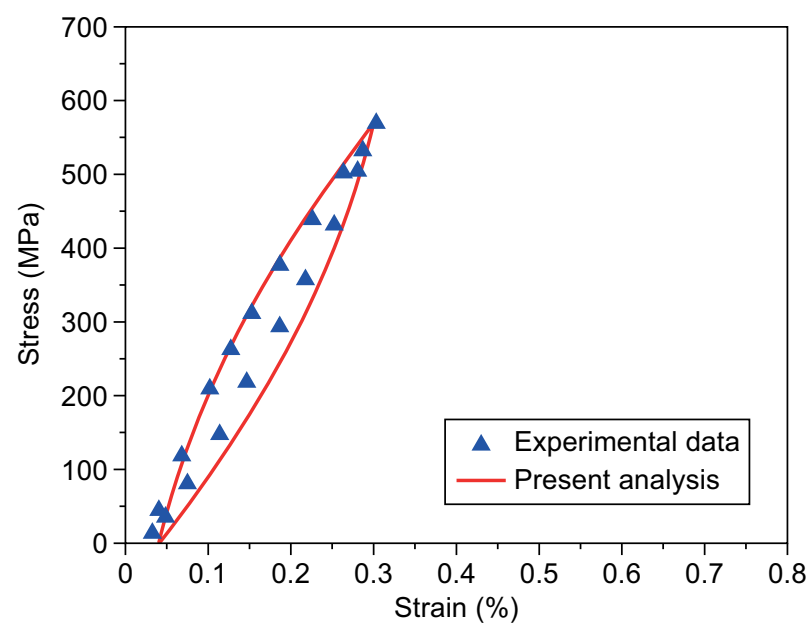

a)

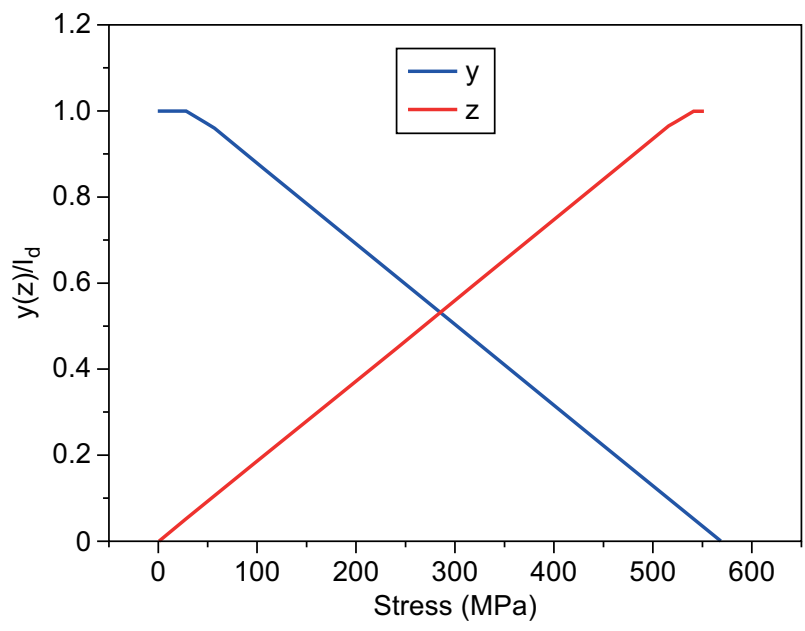

b)

Figure 19. The experimental and predicted fatigue loading/unloading hysteresis loops (a) and the experimental and predicted interface slip length versus the applied stress curves of the Type C Hi-NicalonTM Type S SiC/SiC mini-composite under the peak stress of $\sigma_{\max }=569 \mathrm{MPa}$ (b).

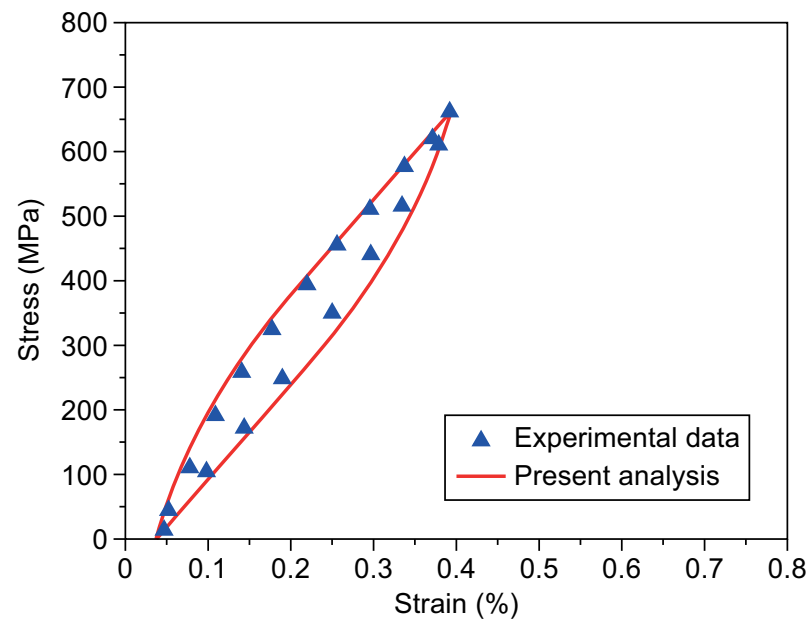

a)

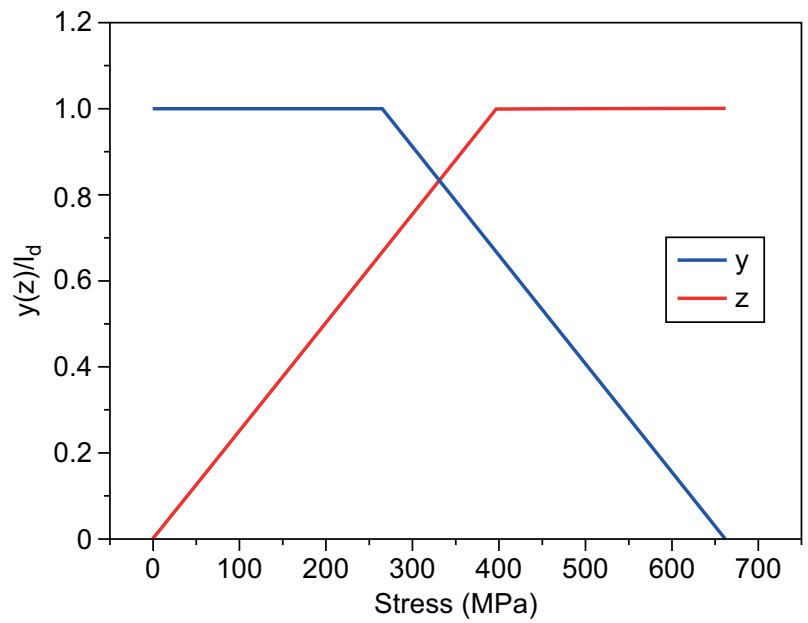

b)

Figure 20. The experimental and predicted fatigue loading/unloading hysteresis loops (a) and the experimental and predicted interface slip length versus the applied stress curves of the Type C Hi-NicalonTM Type S SiC/SiC mini-composite under the peak stress of $\sigma_{\max }=662 \mathrm{MPa}(\mathrm{b})$. 


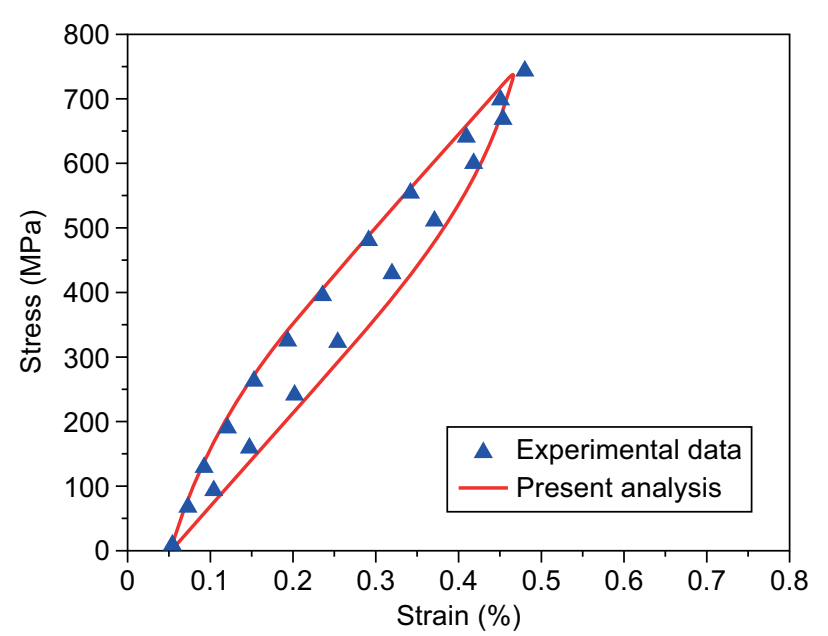

a)

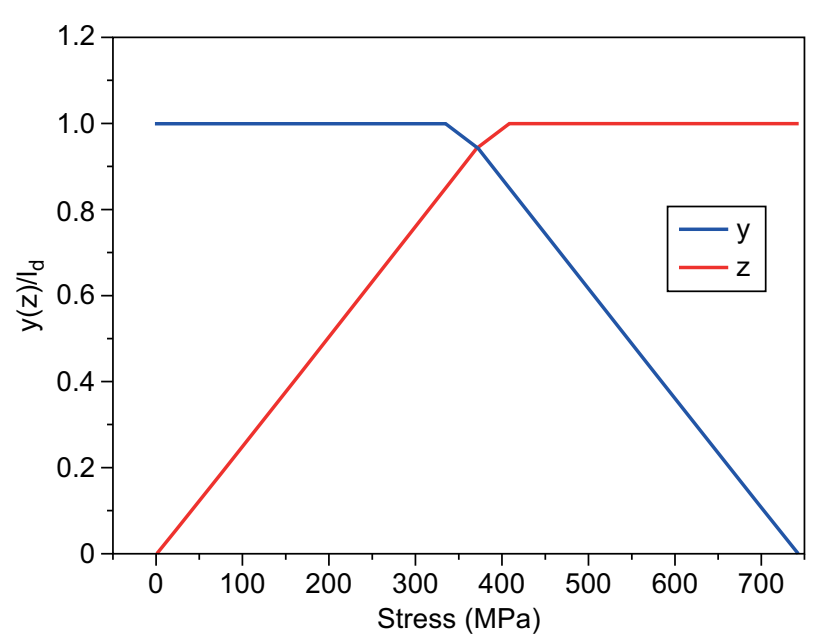

b)

Figure 21. The experimental and predicted fatigue loading/unloading hysteresis loops (a) and the experimental and predicted interface slip length versus the applied stress curves of the Type $\mathrm{C}$ Hi-NicalonTM Type $\mathrm{S} \mathrm{SiC} / \mathrm{SiC}$ mini-composite under the peak stress of $\sigma_{\max }=743 \mathrm{MPa}$ (b).

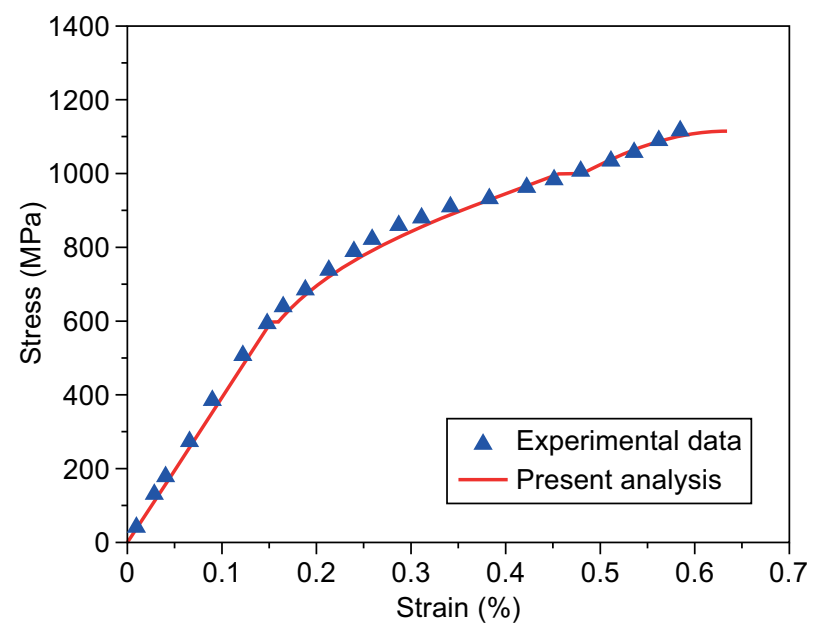

a)

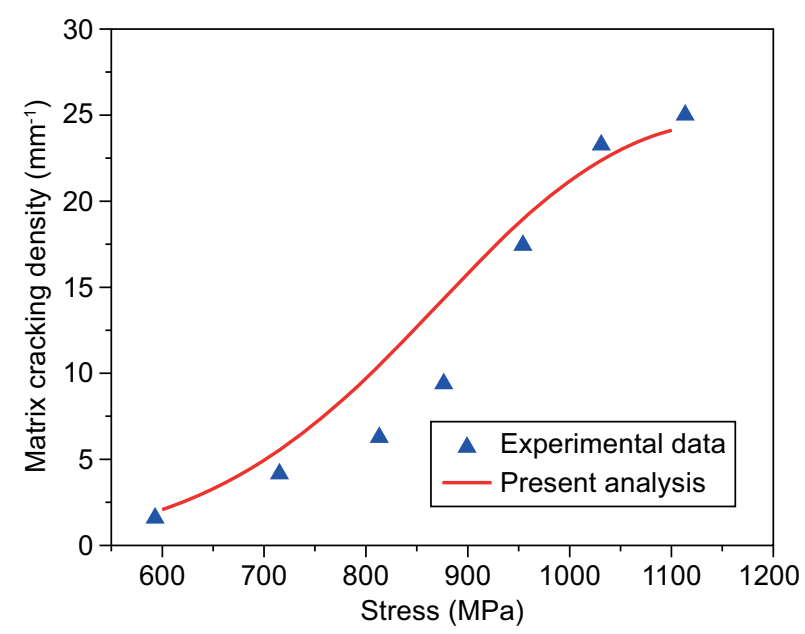

b)

Figure 22. The experimental and predicted tensile stress-strain curves (a) and the experimental and predicted matrix cracking density versus the applied stress curves of the TyrannoTM SA3 SiC/SiC mini-composite (b).

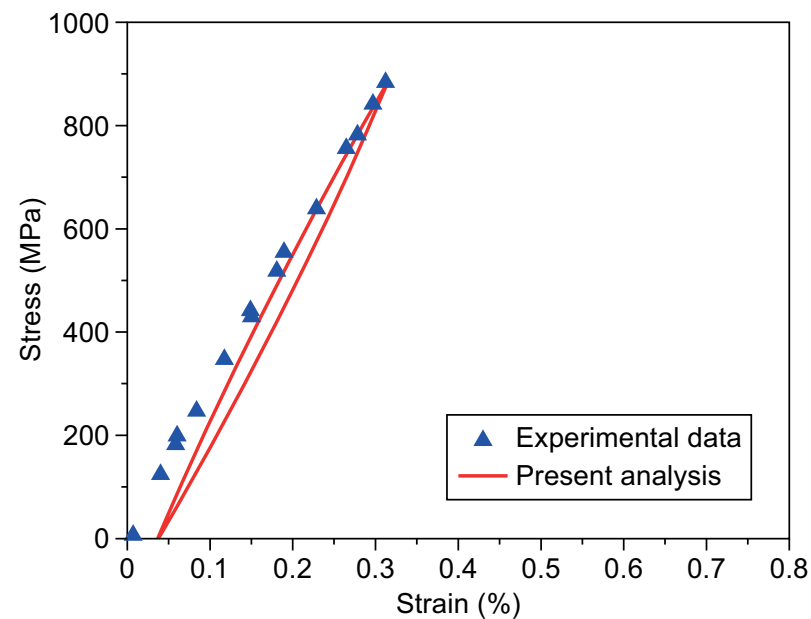

a)

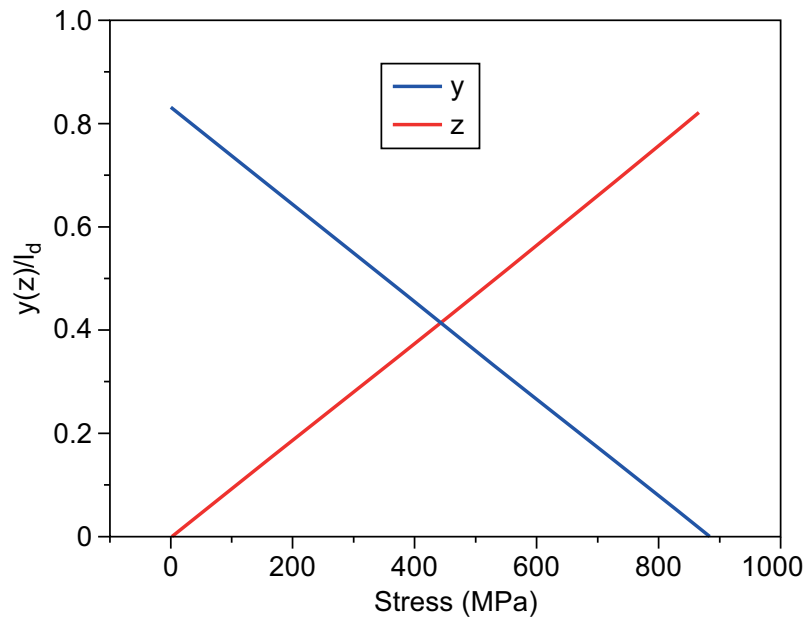

b)

Figure 23. The experimental and predicted fatigue loading/unloading hysteresis loops (a) and the experimental and predicted interface slip length versus the applied stress curves of the TyrannoTM SA3 SiC/SiC mini-composite under the peak stress of $\sigma_{\max }=884 \mathrm{MPa}(\mathrm{b})$. 


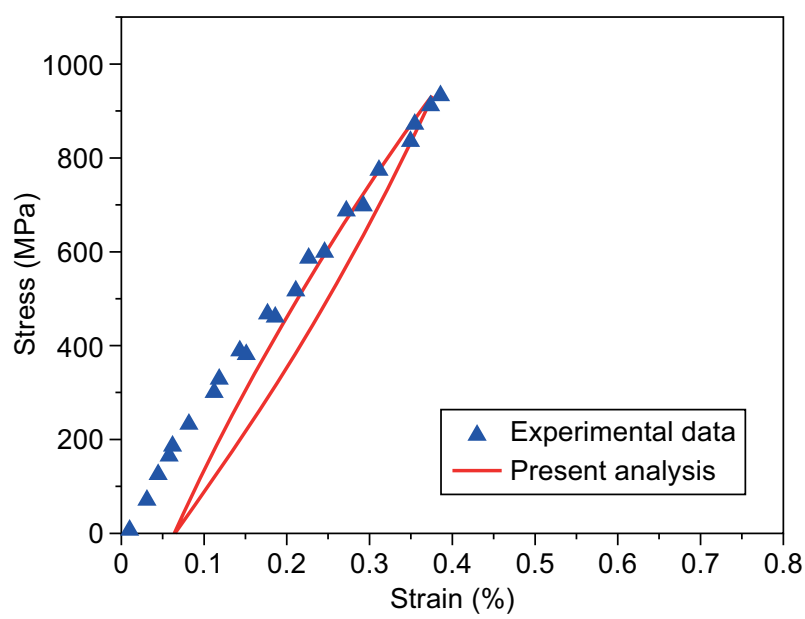

a)

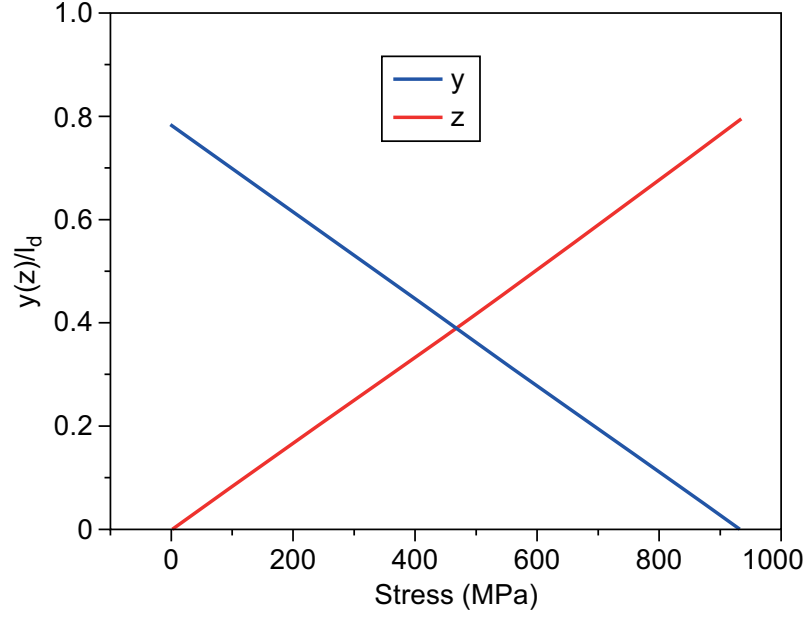

b)

Figure 24. The experimental and predicted fatigue loading/unloading hysteresis loops (a) and the experimental and predicted interface slip length versus the applied stress curves of the TyrannoTM SA3 SiC/SiC mini-composite under the peak stress of $\sigma_{\max }=933 \mathrm{MPa}(\mathrm{b})$.

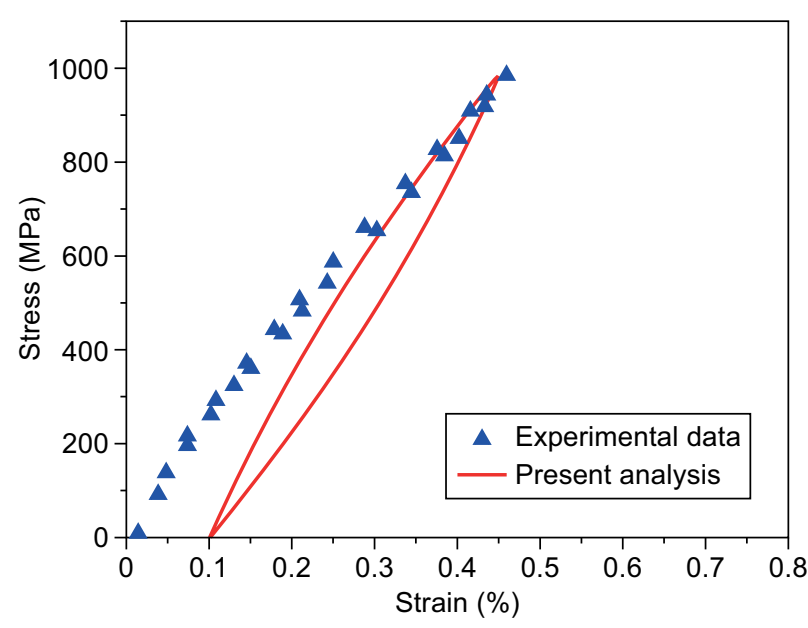

a)

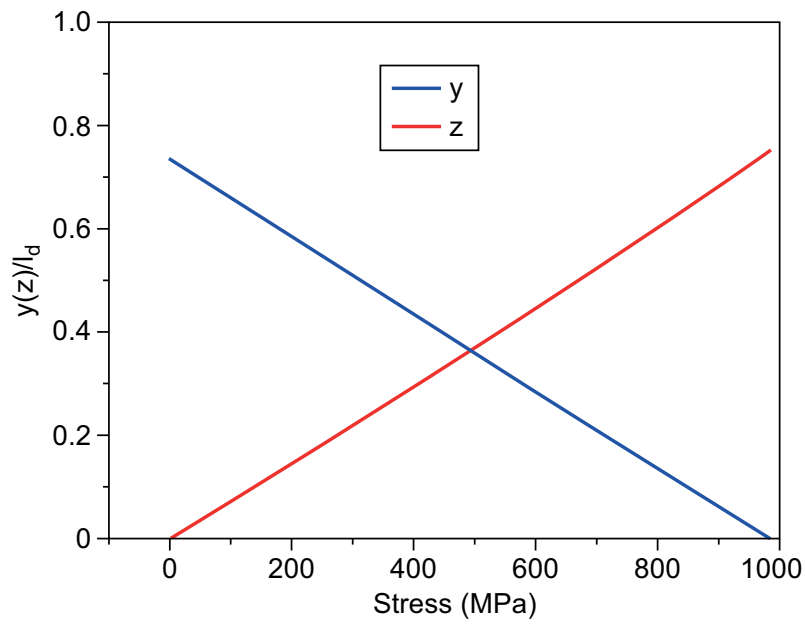

b)

Figure 25. The experimental and predicted fatigue loading/unloading hysteresis loops (a) and the experimental and predicted interface slip length versus the applied stress curves of the TyrannoTM SA3 SiC/SiC mini-composite under the peak stress of $\sigma_{\max }=985 \mathrm{MPa}(\mathrm{b})$.

In the present analysis, there are significant differences between the modelling and experimental data of the matrix cracking density evolution curves. However, the experimental matrix cracking evolution is monitored using the the acoustic emission method, which may take the fibre/matrix interface debonding and the fibre failure signals of the matrix cracking into account, leading to the differences between the experimental and predicted results.

\section{Acknowledgements}

The work reported here is supported by the Fundamental Research Funds for the Central Universities (Grant No. NS2019038).

\section{REFERENCES}

1. Naslain R. (2004): Design, preparation and properties of non-oxide $\mathrm{CMCs}$ for application in engines and nuclear reactors: an overview. Composites Science and Technology, 64(2), 155-170. doi: 10.1016/S0266-3538(03)00230-6

2. DiCarlo J. A., van Roode M. (2006). Ceramic composite development for gas turbine engine hot section components. In: ASME Turbo Expo 2006: Power for Land, Sea, and Air (pp. 221-231). American Society of Mechanical Engineers Digital Collection. doi: 10.1115/GT2006-90151

3. Li L. (2018). Damage, fracture, and fatigue of ceramicmatrix composites. Springer.

4. Li L. (2019). Thermomechanical Fatigue of ceramic-matrix composites. John Wiley \& Sons. doi: 10.1002/9783 527822614

5. Li L. (2019): Temperature-dependent proportional limit stress of carbon fiber-reinforced silicon carbide ceramic- 
matrix composites. Ceramics-Silikaty, 63, 330-337. doi: $10.13168 / \mathrm{cs} .2019 .0028$

6. Li L. (2019): Time-dependent matrix multi-fracture of $\mathrm{SiC} / \mathrm{SiC}$ ceramic-matrix composites considering interface oxidation. Ceramics-Silikaty, 63, 131-148. doi: 10.13168/ cs. 2019.0005

7. Naslain R. (1998): The design of the fiber-matrix interfacial zone in ceramic matrix composites. Composites Part A: Applied Science and Manufacturing, 29(9-10), 1145-1155. doi: 10.1016/S1359-835X(97)00128-0

8. Rebillat, F. (2014). Advances in self-healing ceramic matrix composites. In: Advances in Ceramic Matrix Composites. Woodhead Publishing. pp. 475-514. doi: 10.1533/97808 57098825.2.369

9. Yu H., Zhou X., Zhang W., Peng H., Zhang C. (2013): Mechanical behavior of $\mathrm{SiCf} / \mathrm{SiC}$ composites with alternating $\mathrm{PyC} / \mathrm{SiC}$ multilayer interphases. Materials \& Design, 44, 320-324. doi: 10.1016/j.matdes.2012.07.073

10. Xia Z., Li L. (2014). Understanding interfaces and mechanical properties of ceramic matrix composites. In: Advances in Ceramic Matrix Composites. Woodhead Publishing. pp. 267-285. doi: 10.1533/9780857098825.2.267

11. Li L., Xia Z. (2018). Role of interfaces in mechanical properties of ceramic matrix composites. In: Loe I.M. (Ed.) Advances in Ceramic Matrix Composites. Woodhead Publishing. doi: 10.1016/C2016-0-03477-0

12. Schonfeld K., Klemm H. (2019): Interaction of fiber matrix bonding in $\mathrm{SiC} / \mathrm{SiC}$ ceramic matrix composites. Journal of the European Ceramic Society, 39(13), 3557-3565. doi: 10.1016/j.jeurceramsoc.2019.05.025

13. Li L. (2019): Modeling matrix multi-cracking evolution of fiber-reinforced ceramic-matrix composites considering fiber fracture. Ceramics-Silikaty, 63, 21-31. doi: $10.13168 / \mathrm{cs} .2018 .0042$

14. Zhu S., Mizuno M., Nagano Y., Kagawa Y., Kaya H. (1998): Tensile creep behavior of a $\mathrm{SiC}$-fiber/SiC composite at elevated temperatures. Composites Science and Technology, 57, 1629-1637. doi: 10.1016/S0266-3538(97)00095-X

15. Li H., Morscher G. N., Lee J., Lee W. Y. (2004): Tensile and Stress-Rupture Behavior of $\mathrm{SiC} / \mathrm{SiC}$ Minicomposite Containing Chemically Vapor Deposited Zirconia Interphase. Journal of the American Ceramic Society, 87(9), 1726-1733. doi: 10.1111/j.1551-2916.2004.01726.x

16. Wang K., Chen L., Zheng X. (2010): Comparisons of tensile behavior of plain-woven carbon/silicon carbide composites at room temperature and high temperature. Journal of Aeronautical Materials, 30, 78-84.

17. Jing X., Yang X., Shi D., Niu H. (2017): Tensile creep behavior of three-dimensional four-step braided $\mathrm{SiC} / \mathrm{SiC}$ composite at elevated temperature. Ceramics International, 43, 6721-6729. doi: 10.1016/j.ceramint.2017.02.076

18. Li L. (2018): Modeling the monotonic and cyclic tensile stress-strain behavior of $2 \mathrm{D}$ and $2.5 \mathrm{D}$ woven $\mathrm{C} / \mathrm{SiC}$ ceramic-matrix composites. Mechanics of Composite Materials , 54:165-178. doi: 10.1007/s11029-018-9729-5

19. Li L. (2019): A thermomechanical fatigue hysteresis-based damage evolution model for fiber-reinforced ceramic-matrix composites. International Journal of Damage Mechanics, 28(3), 380-403. Doi: 10.1177/1056789518772162

20. Li L. (2019): Micromechanics modeling of fatigue hysteresis behavior in carbon fiber-reinforced ceramic-matrix composites. Part I: Theoretical analysis. Composites Part B, 159, 502-513. doi: 10.1177/1056789518772162
21. Godin N., Reynaud P., Fantozzi G. (2019): Contribution of $\mathrm{AE}$ analysis in order to evaluate time to failure of ceramic matrix composites. Engineering Fracture Mechanics, 210, 452-469. doi: 10.1016/j.engfracmech.2018.03.006

22. Wang Y., Zhang L., Cheng L., Ma J., Zhang W. (2008): Tensile performance and damage evolution of a 2.5-D $\mathrm{C} / \mathrm{SiC}$ composite characterized by acoustic emission. Applied Composite Materials, 15(4-6), 183-188. doi: 10. 1007/s10443-008-9066-2

23. Evans A.G., Domergue J.M., Vagaggini E. (1994): Methodology for relating the tensile constitutive behavior of ceramic-matrix composites to constituent properties. Journal of the American Ceramic Society, 77(6), 1425-1435. doi: 10.1111/j.1151-2916.1994.tb09739.x

24. Sorensen B.F., Holmes J.W. (1996): Effect of loading rate on the monotonic tensile behavior of a continuous-fiberreinforced glass ceramic matrix composite. Journal of the American Ceramic Society, 79, 313-320. doi: 10.1111/ j.1151-2916.1996.tb08122.x

25. Ruggles-Wrenn M.B., Radzicki A.T., Baek S.S., Keller K.A. (2008): Effect of loading rate on the monotonic tensile behavior and tensile strength of an oxide-oxide ceramic composite at $1200^{\circ} \mathrm{C}$. Materials Science and Engineering: A, 492(1-2), 88-94. doi: 10.1016/j.msea.2008.03.006

26. Mei H., Bai Q., Li H., Yu C., Cheng L. (2014): Effect of loading rate and temperature on monotonic tensile behavior in two-dimensional $\mathrm{C} / \mathrm{SiC}$ composites. Ceramics International, 40, 16635-16640. doi: 10.1016/j.ceramint. 2014.08.024

27. Zhu S., Gomyou T., Ochi Y., Ogasawara T. (2004): Effects of loading rate and temperature on tensile behavior of orthogonal three-dimensional woven $\mathrm{Si}-\mathrm{Ti}-\mathrm{C}-\mathrm{O}$ fiber/SiTi-C-O matrix composites. Journal of Materials Research, 19(10), 2964-2973. doi: 10.1557/JMR.2004.0375

28. Ahn B.K., Curtin W.A., Parthasarathy T.A., Dutton R.E. (1998): Criterion for crack deflection/penetration criterion for fiber-reinforced ceramic matrix composites. Composites Science and Technology, 58(11), 1775-1784. doi: 10.1016/ S0266-3538(98)00043-8

29. Carrere N., Martin E., Lamon J. (2000): The influence of the interphase and associated interfaces on the deflection of matrix cracks in ceramic matrix composites. Composites Part A: Applied Science and Manufacturing, 31(11), 1179-1190. doi: 10.1016/S1359-835X(00)00095-6

30. Sauder C., Brusson A., Lamon J. (2010): Influence of interface characteristics on the mechanical properties of Hi-Nicalon type-S or Tyranno-SA3 fiber-reinforced SiC/ $\mathrm{SiC}$ minicomposites. International Journal Of Applied Ceramic Technology, 7(3), 291-303. doi: 10.1111/j.17447402.2010.02485.x

31. YuH.,ZhouX.,ZhangW.,PengH.,Zhang C.(2013):Influence of $\mathrm{SiC}$ coating thickness on mechanical properties of $\mathrm{SiC} / \mathrm{SiC}$ composite. Journal of Nuclear Materials, 442(1-3), 53-59. doi: 10.1016/j.jnucmat.2013.08.038

32. Kabel J., Yang Y., Balooch M., Howard C., Koyanagi T., Terrani K.A., Katoh Y., Hosemann P. (2017): Micromechanical evaluation of SiC-SiC composite interphase properties and debond mechanisms. Composites Part B: Engineering, 131, 173-183. doi: 10.1016/j.compositesb. 2017.07.035

33. Pryce A.W., Smith P.A. (1992): Behavior of unidirectional and crossply ceramic matrix composites under quasi-static tensile loading. Journal of Materials Science, 27(10), 2695-2704. doi: 10.1007/BF00540692 
34. Pryce A.W., Smith P.A. (1993): Matrix cracking in unidirectional ceramic matrix composites under quasi-static and cyclic loading. Acta Metallurgica et Materialia, 41(4), 1269-1281. doi: 10.1016/0956-7151(93)90178-U

35. Chateau C., Gelebart L., Bornert M., Crepin J., Caldemaison D., Sauder C. (2014): Modeling of damage in unidirectional ceramic matrix composites and multi-scale experimental validation on third generation $\mathrm{SiC} / \mathrm{SiC}$ minicomposites. Journal of the Mechanics and Physics of Solids, 63, 298-319. doi: 10.1016/j.jmps.2013.09.001

36. Morscher G.N., Sing M., Kiser J.D., Freedman M., Bhatt R. (2007): Modeling stress-dependent matrix cracking and stress-strain behavior in 2D woven $\mathrm{SiC}$ fiber reinforced CVI SiC composites. Composites Science and Technology, 67(6), 1009-1017. doi: 10.1016/j.compscitech.2006.06.007

37. Li L., Song Y., Sun Y. (2014): Modeling the tensile behavior of unidirectional $\mathrm{C} / \mathrm{SiC}$ ceramic-matrix composites. Mechanics of Composite Materials, 49(6), 659-672. doi: 10.1007/ s11029-013-9382-y

38. Li L., Song Y., Sun Y. (2013): Modeling loading/unloading hysteresis behavior of unidirectional $\mathrm{C} / \mathrm{SiC}$ ceramic matrix composites. Applied Composite Materials, 20(4), 655-672. doi: 10.1007/s10443-012-9294-3

39. Li L. (2018): Modeling out-of-phase thermomechanical fatigue hysteresis of long fiber-reinforced ceramic-matrix composites subjected to different loading sequences. Journal of the Ceramic Society of Japan, 126(5), 346-353. doi: $10.2109 /$ jcersj2.17233

40. Li L. (2019): Damage and fracture of fiber-reinforced ceramic-matrix composites under thermal fatigue loading in oxidizing atmosphere. Journal of the Ceramic Society of Japan, 127, 67-80. doi: 10.2109/jcersj2.18107

41. Lamon J., Rebillat F., Evans A.G. (1995): Microcomposite test procedure for evaluating the interface properties of ceramic matrix composites. J Journal of the American Ceramic Society, 78, 401-405. doi: 10.1111/j.1151-2916. 1995.tb08814.x

42. Guillaumat L., Lamon J. (1996): Fracture statistics applied to modeling the non-linear stress-strain behavior in microcomposites: Influence of interfacial parameters. International Journal of Fracture, 82(4), 297-316. doi: 10.1007/ BF00013235

43. Morscher G.N., Martinez-Fernandez J., Purdy M.J. (1996): Determination of interfacial properties using a single-fiber microcomposite test. Journal of the American Ceramic Society, 79, 1083-1091. doi: 10.1111/j.1151-2916.1996. tb08551.x

44. Cho C.D., Holmes J.W., Barber J.R. (1991): Estimation of interfacial shear in ceramic composites from frictional heating measurements. Journal of the American Ceramic Society, 74, 2802-2808. doi: 10.1111/j.1151-2916.1991. tb06846.x

45. Holmes J.W., Cho C.D. (1992): Experimental observation of frictional heating in fiber-reinforced ceramics. Journal of the American Ceramic Society, 75, 929-938. doi: 10.1111/ j.1151-2916.1992.tb04162.x

46. Staehler J.M., Mall S., Zawada L.P. (2003): Frequency dependence of high-cycle fatigue behavior of $\mathrm{CVI} \mathrm{C/SiC} \mathrm{at}$ room temperature. Composites Science and Technology, 63, 2121-2131. doi: 10.1016/S0266-3538(03)00190-8
47. Evans A.G., Zok F.W., McMeeking R.M. (1995): Fatigue of ceramic matrix composites. Acta Metallurgica et Materialia, 43, 859-875. doi: 10.1016/0956-7151(94)00304-Z

48. Reynaud P. (1996): Cyclic fatigue of ceramic-matrix composites at ambient and elevated temperatures. Composites Science and Technology, 56, 809-814. doi: 10.1016/02663538(96)00025-5

49. Zhu S., Mizuno M., Kagawa Y., Mutoh Y. (1999): Monotonic tension, fatigue and creep behavior of SiC-fiber-reinforced SiC-matrix composites: a review. Composites Science and Technology, 59, 833-851. doi: 10.1016/S02663538(99)00014-7

50. Fantozzi G., Reynaud P. (2009): Mechanical hysteresis in ceramic matrix composites. Materials Science and Engineering: A, 521, 18-23. doi: 10.1016/j.msea.2008.09.128

51. Ruggles-Wrenn M.B., Christensen D.T., Chamberlain A.L., Lane J.E., Cook T.S. (2011): Effect of frequency and environment on fatigue behavior of a $\mathrm{CVI} \mathrm{SiC} / \mathrm{SiC}$ ceramic matrix composite at $1200{ }^{\circ} \mathrm{C}$. Composites Science and Technology, 71, 190-196. doi: 10.1016/j.compscitech. 2010.11.008

52. Dassios K.G., Aggelis D.G., Kordatos E.Z., Matikas T.E. (2013): Cyclic loading of a SiC-fiber reinforced ceramic matrix composite reveals damage mechanisms and thermal residual stress state. Composites Part A: Applied Science and Manufacturing, 44, 105-113. doi: 10.1016/j. compositesa.2012.06.011

53. Li L. (2019): Synergistic effects of frequency and temperature on fatigue hysteresis of cross-ply SiC/MAS composite under tension-tension loading. Ceramics-Silikáty, 63, 51-66. doi:10.13168/cs.2018.0045

54. Li L. (2018): Modeling in-phase thermomechanical fatigue hysteresis loops of fiber-reinforced ceramic-matrix composites. Ceramics-Silikáty, 62, 240-247. doi: 10.13168/ cs.2018.0017

55. Morscher G.N., Baker C. (2014): Electrical resistance of $\mathrm{SiC}$ fiber reinforced $\mathrm{SiC} / \mathrm{Si}$ matrix composites at room temperature during tensile testing. International Journal of Applied Ceramic Technology, 11(2), 263-272. doi: 10.1111/ ijac. 12175

56. Han Z., Morscher G. N. (2015). Electrical resistance and acoustic emission during fatigue testing of $\mathrm{SiC} / \mathrm{SiC}$ composites. In: Mechanical Properties and Performance of Engineering Ceramics and Composites X. doi: 10.1002/ 9781119211310.ch4

57. Budiansky B., Hutchinson J.W., Evans A.G. (1986): Matrix fracture in fiber-reinforced ceramics. Journal of the Mechanics and Physics of Solids, 34(2), 167-189. doi: 10.1016/0022-5096(86)90035-9

58. Lissart N., Lamon J. (1997): Damage and failure in ceramic matrix minicomposites: Experimental study and model. Acta Materialia, 45(3), 1025-1044. doi: 10.1016/S13596454(96)00224-8

59. Li L., Song Y. (2010): An approach to estimate interface shear stress of ceramic matrix composites from hysteresis loops. Applied Composite Materials, 17(3), 309-328. doi: 10.1007/s10443-009-9122-6

60. Vagaggini E., Domergue J.-M., Evans A.G. (1995): Relationships between hysteresis measurements and the constituent properties of ceramic matrix composites: I Theory. Journal of the American Ceramic Society, 78, 2709-2720. doi: 10.1111/j.1151-2916.1995.tb08046.x 